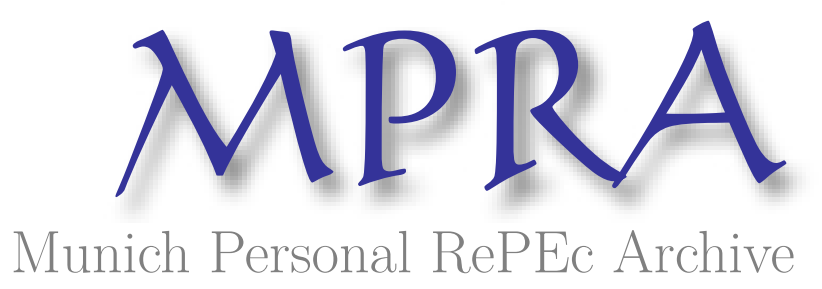

\title{
Income inequality, consumption, credit and credit risk in a data-driven agent-based model
}

Papadopoulos, Georgios

Analysis and Research Centre, Bank of Slovenia

30 October 2018

Online at https://mpra.ub.uni-muenchen.de/89764/

MPRA Paper No. 89764, posted 06 Nov 2018 14:59 UTC 


\title{
Income inequality, consumption, credit and credit risk in a data-driven agent-based model
}

\author{
Georgios Papadopoulos* \\ Analysis and Research Centre, Bank of Slovenia, Ljubljana, \\ Slovenia \\ georgios.papadopoulos@bsi.si
}

\begin{abstract}
The issue of income inequality occupies a prominent position in the research agenda of academic and policy circles alike, especially after the crisis of 2008, due to its potential causal link with the development of credit bubbles and therefore the emergence of financial crises. This paper examines the long-run effect of income inequality on consumption, consumer credit and non-performing loans through the means of a datadriven agent-based model. The data-driven nature of the model enhances its ability to match historical series and thus makes it suitable for policy simulations tailored for specific economies. The analysis indicates that higher income inequality has a detrimental impact on consumption and is associated with lower volumes of consumer credit. However, the ratio of non-performing loans as a share of total loans seems to be independent of income inequality.
\end{abstract}

JEL classification: C63; D31; E21; E27

Keywords: Income inequality; Consumption; Consumer credit; Nonperforming loans; Agent-based model

${ }^{*}$ The idea for this project was conceived while the author was attending Santa Fe Institute's Complexity Explorer MOOC "Introduction to Agent-Based Modeling" for which a scholarship is gratefully acknowledged. The author would like to thank Professor Bill Rand, Complexity Explorer's team and fellow MOOC students, the organizers and participants of the University of Trento's XIX Trento Summer School in Adaptive Economic Dynamics, Elisa Reinhold and participants of internal Bank of Slovenia seminars for useful comments and suggestions. This paper should not be reported as representing the views of the Bank of Slovenia or the European System of Central Banks. The views expressed are those of the author and do not necessarily reflect those of any of the aforementioned institutions. 


\section{Introduction}

The central theme of this paper is the effect of inequality in the distribution of income on aggregate macroeconomic and financial variables. At its core is essentially a thought experiment attempting to answer the question: How would the initial level of income inequality affect aggregate consumption, consumer credit and non-performing loans of an economic system which would otherwise follow a specific historical scenario?

The issue of inequality and the effects of its various manifestations -such as income, wealth or consumption- on both developing and developed countries has attracted the attention of academia and policy makers alike ${ }^{1}$, especially after the financial crisis of 2008 , with several studies documenting significant increases in the skewness and kurtosis of income and wealth distributions over the past three decades (e.g. Piketty and Saez (2003, 2006), Atkinson and Morelli (2011)). However, this topic might not have risen to such prominent position within the economics profession if it weren't for the potential causal links between rising inequality and financial crises.

The rationale behind this cause and effect relationship begins with households with insufficient financial resources resorting to borrowing in order to maintain their living standards. In turn, the excess leverage creates unsustainable credit growth which subsequently ends with a credit bubble bust. One of the consequences of the latter is the amplification of pre-existing inequalities thus resulting in a positive feedback loop between inequality and crises. For a review of the recent literature on the complex interconnections between inequality, leverage and crises the reader is referred to the excellent work of Bazillier and Héricourt (2017) and references therein.

Interestingly, empirical literature on the first, fundamental element of the hypothesized underlying mechanism linking higher inequality with increased volumes of credit is not conclusive. Results range from suggesting a positive (Christen and Morgan, 2005; Perugini et al., 2015), negative (Coibion et al., 2014) or even non-significant (Bordo and Meissner, 2012) relationship. On the contrary, theoretical works display a higher consensus regarding the sign and the direction of the aforementioned relationship. Contributions from the DSGE literature (Iacoviello, 2008; Kumhof et al., 2015) show how increased inequality can create highly indebted, low-income households which eventually results in a fragile economy, prone to financial and real crises.

Another strand of literature employs agent-based models $(\mathrm{ABM})^{2}$ to explore the economic effects of various inequality forms such as income (Cardaci and Saraceno, 2015; Dosi et al., 2013, 2015, 2016; Palagi et al., 2017), wealth (Russo et al., 2016) or both (Caiani et al., 2017) and indeed finds that higher inequality has detrimental macroeconomic effects, impeding growth and increasing the

\footnotetext{
${ }^{1}$ For the latter see Amaral (2017), Colciago et al. (2018) or Ampudia et al. (2018) and references therein for studies on the relationship between central bank policies and inequality.

${ }^{2}$ For an elaborate exposition of this modelling approach in macroeconomics see Dawid and Delli Gatti (2018) while for its differences with DSGE models see Fagiolo and Roventini (2017) and references therein.
} 
probability of a crisis occurring.

The bottom-up nature of ABM makes this approach flexible and appropriate to examine distributional questions, hence it will be followed in this study. However, contrary to the aforementioned works where fully-fledged models are developed with all interactions among agents being endogenously determined, in this paper certain agents are not explicitly modelled. Instead, for simplicity, their interactions with the other agents enter the model exogenously, as input from historical data ${ }^{3}$ (Hassan et al., 2010).

This modelling choice allows to simplify the interaction structure among agents to a large extent by forcing them to follow as closely as possible the actual evolution of several key variables. This specific approach has two benefits. Firstly, it enables the targeted examination of the effect of a single parameter, namely income inequality, on the variables under study. Secondly, it permits to bring the model closer to the data than the current standard in the ABM literature in economics which is the replication of empirical regularities. ${ }^{4} \mathrm{By}$ doing so, the empirical validation of the model extends beyond matching stylized facts between simulated and actual data, to directly comparing the evolution of the historical with the artificially generated time series. This enables to use the model for policy simulations referring to specific economies, in addition to answering the core question on the impact of the initial level of income inequality on macro-financial variables.

The remainder of the paper is organized as follows. In section 2 the model's structure is described in detail. Agents' behavioural rules and interactions in the various markets are elaborated, including a crucial element which is their expectations formation mechanism. Section 3 initially describes the input data used and presents the outcome of model's validation before proceeding with the presentation and discussion of the simulation results. Finally, section 4 concludes exploring potential uses and extensions of the model.

\section{The model}

This section provides a description of the modelling properties which characterise the agent-based, macroeconomic model under development. The most elaborate agents of the economic system are households $(h=1,2, \ldots, H)$ and banks, represented as an all-encompassing banking sector agent. For the remaining agents such as firms, the central bank and the government historical data are used to determine the evolution of their interactions with the former

\footnotetext{
${ }^{3}$ Thus, it is closely related to the "history-friendly" approach to calibration identified by Fagiolo et al. (2007).

${ }^{4}$ The vast majority of the respective literature has focused on the adequate replication of empirical stylized facts and regularities (Fagiolo et al., 2017). Two of the most successful attempts so far showing a good fit between artificial time series from an ABM and the actual ones have been by Geanakoplos et al. (2012) and Delli Gatti et al. (2011). In the former the authors use data from 2.2 million households to model the housing market of the greater Washington, DC area while in the latter the authors use data for 25,000 Italian firms to validate their macroeconomic ABM.
} 
agents in the respective markets.

The economic system evolves over $t=1,2, \ldots, T$ time periods, with $T$ being determined by the time range of the historical data used. As follows from the focus of agents' development, the most detailed market in which they interact is the credit market. All other markets are passive and their evolution is governed by that of the historical series.

Households are boundedly rational and simple heuristics control their behaviour. If their financial position allows them, they consume a proportion of their expected income and past deposits in each period and save any remaining resources. Otherwise, in case they are in financial distress, they consume a minimum amount or they ask for credit if their financial position is sound. A key role in credit demand is played by the households' income expectations formation mechanism. Based on the heuristics switching model (HSM) of Anufriev and Hommes (2012a,b), households follow simple linear, adaptive and trend extracting rules to form their expectations. In addition, their chosen rule is not fixed but they update their selection from a small pool of expectation heuristics according to their past performance. As pointed out by De Grauwe and Macchiarelli (De Grauwe and Macchiarelli, 2015) it is indeed rational to utilize simple forecasting heuristics and monitor their performance given one's limited cognitive capabilities.

On the supply-side of credit, the bank bases its decision to provide credit on its available deposits and a time-variant measure proxying its risk tolerance, namely the debt service to income ratio (DSTI).

Finally, the labour market is entirely data-driven. The monthly evolution of households' income and their employment status enter the model as input from historical data. Households' income, there being no explicitly modelled government agent and thus no taxes, corresponds to their disposable income. For brevity, in the remainder of the paper income will be used to refer to disposable income. Unemployed households receive an unemployment benefit from the government which is assumed to coincide with the subsistence consumption level. It should be noted that the only interaction between the implicit government agent and households is through the unemployment benefit.

In the following subsections are described the initialization of the simulation, the timeline of events taking place at each period and subsequently the agents and their interactions in the respective markets.

\subsection{Initialization}

One of the prerequisites for a micro-founded ABM is that agents' initial conditions should be initialized with actual data (Delli Gatti et al., 2011). At the beginning of the simulation each household is endowed with a monthly income ${ }^{5}$ drawn from a gamma distribution, $\Gamma(\alpha, 1 / \lambda)$ with $\alpha$ and $\lambda$ the shape and scale

\footnotetext{
${ }^{5}$ Computationally, the algorithm described in Hamill and Gilbert (2015) is used to allocate households' income.
} 
parameters respectively. ${ }^{6}$ By adjusting the shape and scale one can specify the distribution so that it has the same average and minimum values as well as the same degree of inequality as the historical distribution. It should be noted that, for a given $\alpha$, the smaller the $\lambda$ the less skewed the distribution, i.e. the lower the inequality.

The initialization of the unemployment rate is also based on its historical figures at the start of the simulation. According to these, a number of households is chosen randomly and their income is fixed at the level of the unemployment dole which permits them to maintain the minimum consumption level required to survive.

After the initialization of income and unemployment all growth rates are set to zero and the simulation is executed for a burn-in period of $N$ time steps, after which the system is assumed to have reached its equilibrium. After that period the historical data enter into the model and its output is recorded.

\subsection{Sequence of events}

The sequence of events in every period of the simulation is the following:

1. Historical series for income and unemployment growth as well as loan and deposit interest rates are updated.

2. The bank sets its DSTI level.

3. Households collect the interest from any deposits they have placed at the bank.

4. Employed households receive their monthly income based on the aforementioned historical growth rates.

5. The historical evolution of unemployment determines households' employment status.

6. Households update their income expectations.

7. Households address their financial obligations and determine their desired consumption.

8. Households with insufficient own financial resources to meet their desired consumption ask for credit.

9. The bank calculates and offers the maximum amount of credit it can to a household given its DSTI and the income of the latter.

10. Households meet their desired consumption or a fraction of it in case they are financially constrained and deposit any remaining income.

\footnotetext{
${ }^{6}$ Empirical studies show that from the family of two-parameter distributions, gamma distribution fits income data reasonably well in a variety of countries and different periods in time (Bandourian et al., 2002).
} 


\subsection{Agent and market description}

This subsection provides a detailed description of the agents, their behavioural rules and interactions in the various markets.

\subsubsection{Households}

Households' consumption decisions crucially depend on their financial position and in particular their ability to consume the minimum amount which ensures their survival. This is summarized in the following rule:

$C_{h, t}^{d}= \begin{cases}C_{\min , t}, & I_{h, t}+D_{h, t-1}<L P_{h, t}+C_{\min , t} \\ \max \left\{\alpha_{y} \cdot I_{h, t+1}^{e}+\alpha_{w} \cdot D_{h, t-1}, C_{\min , t}\right\}, & I_{h, t}+D_{h, t-1} \geq L P_{h, t}+C_{\min , t}\end{cases}$

with $0<\alpha_{w}<\alpha_{y}<1$ the marginal propensities to consume out of wealth and income respectively.

Those households whose sum of current income $\left(I_{h, t}\right)$ and past deposits $\left(D_{h, t-1}\right)$ does not suffice for them to consume the minimum amount $\left(C_{m i n, t}\right)$ and meet their monthly loan payment $\left(L P_{h, t}\right)$, set their desired consumption $\left(C_{h, t}^{d}\right)$ to that of the subsistence level. It follows that they don't service any loans they might have for as long as these conditions remain. On the contrary, households who can afford minimum consumption and service their loan they do so and set their desired consumption as the largest element between a percentage of their expected income $\left(I_{h, t+1}^{e}\right)$ and past deposits and $C_{m i n, t}$.

The specific Modigliani (Modigliani and Brumberg, 1954) consumption function of the financially sound households in Equation (1) is thoroughly discussed in Godley and Lavoie (2016) and is widely used by the respective ABM literature (Delli Gatti and Desiderio, 2015; Gualdi et al., 2015; Ricetti et al., 2013; Riccetti et al., 2015; Assenza et al., 2015; Caiani et al., 2016; Russo et al., 2016; Gurgone et al., 2018; Meijers et al., 2018, among others). ${ }^{7}$ Although such rule may seem overly simple, Allen and Carroll (2001) argue that linear, ruleof-thumb consumption functions can indeed provide a good approximation of consumption functions -such as the one from buffer stock theory- derived as solutions to utility maximization problems. One interesting implication of the linear consumption function of Equation (1) is that households have a target wealth to income ratio of $\left(1-\alpha_{y}\right) / \alpha_{w}$. Therefore, in an attempt to reach it, they save when their target level of wealth is higher than the realized one (Godley and Lavoie, 2016).

In case a household's remaining income and deposits (i.e. after servicing its loan) is enough to meet its desired level of consumption, it uses its own financial resources (withdrawing from its deposits if need be) to satisfy it. Otherwise it asks for consumer credit from the bank. A household asking for credit is assumed to spend any amount granted along with all of its income plus deposits

\footnotetext{
${ }^{7}$ For more examples of consumption functions used in various macroeconomic ABMs the reader is referred to the works of Haldane and Turrell (2018) and Dawid and Delli Gatti (2018) and references therein.
} 
to satisfy its desired consumption. Thus, it may consume less or more than desired depending on the supplied credit.

Finally, after consumption plans are executed, any income remaining is deposited at the bank at the given overnight deposit interest rate.

\subsubsection{Expectations formation}

Due to the pivotal role expectations play in credit demand in the model, their formation mechanism merits an elaborate description.

Research on expectations formation has identified three key facts regarding individuals' behaviour:

- Expectations are heterogeneous among individuals.

- Individuals use simple linear (adaptive and trend extrapolating) heuristics to form their expectations.

- Individuals switch among heuristics.

These findings are supported by a large number of studies using both survey data (Mankiw et al., 2003; Branch, 2004; Pfajfar and Santoro, 2010) and in controlled experiments (Hommes et al., 2004, 2008; Haruvy et al., 2007; Pfajfar and Žakelj, 2016; Assenza et al., 2011).

Following the seminal papers by Brock and Hommes $(1997,1998)$, the works of Anufriev and Hommes (2012a,b) have established that individual and aggregate experimental data can be adequately described by a heuristics switching model (HSM).

In particular, the HSM rests on four simple heuristics, evaluated on the basis of their performance and selected according to a discrete choice model with asynchronous updating (Diks and Van Der Weide, 2005; Hommes et al., 2005).

The expectations heuristics for a generic variable $y_{t}$ are the following:

Weak trend following rule (WTR):

$$
y_{w t r, t}^{e}=y_{t-1}+\omega_{w t r} \cdot\left(y_{t-1}-y_{t-2}\right)
$$

Strong trend following rule (STR):

$$
y_{s t r, t}^{e}=y_{t-1}+\omega_{s t r} \cdot\left(y_{t-1}-y_{t-2}\right)
$$

Adaptive expectations rule (ADA):

$$
y_{a d a, t}^{e}=y_{t-1}^{e}+\omega_{a d a} \cdot\left(y_{t-1}-y_{t-1}^{e}\right)
$$

Learning anchoring and adjustment rule (LAA):

$$
y_{l a a, t}^{e}=\frac{y_{t-1}^{a v}+y_{t-1}}{2}+\left(y_{t-1}-y_{t-2}\right)
$$


, where $y_{t-1}^{a v}=\frac{1}{t} \sum_{j=0}^{j=t-1} y_{j}$

The first two heuristics (WTR and STR) represent a trend-following rule which extrapolates the latest change from the most recent observation of $y$. Their difference is in how strong the reaction to past changes is with $\omega_{s t r}>\omega_{w t r}$. Expectations under the adaptive rule (ADA) are formed as a weighted average of the current observation and its expected value and, finally, the LAA heuristic is a slightly more complicated trend-following rule which extrapolates the last observed change from an anchor (hence its name). The latter is the average between the last observed value of $y$ and the mean of its past values (Anufriev and Hommes, 2012a,b).

The performance measure of heuristic $i$ is:

$$
U_{i, t-1}=-\left(y_{t-1}-y_{i, t-1}^{e}\right)^{2}+\eta U_{i, t-2}
$$

The parameter $\eta \in[0,1]$ denotes the strength of households' memory, or put differently, the relative weight they assign to past errors. In the case of $\eta=0$, past performance is completely forgotten and only current one matters. For every other value of $\eta \in(0,1]$ all past prediction errors are taken into account.

Households employ a specific expectations heuristic with probability $n_{i, t}$, which is updated in every period accordingly:

$$
n_{i, t}=\delta n_{i, t-1}+(1-\delta) \frac{\exp \left(\beta U_{i, t-1}\right)}{\sum_{i=1}^{4} \exp \left(\beta U_{i, t-1}\right)}
$$

The parameter $\delta \in[0,1]$ captures households' willingness to switch among heuristics (i.e. their persistence) and the parameter $\beta \geq 0$ measures the intensity of choice representing households' sensitivity to differences in heuristic performance.

In the model, the values of every parameter associated with the HSM are set according to the ones identified by Anufriev and Hommes (2012a,b) and are reported in Table 4.

\subsubsection{Bank}

The banking sector is represented by a single agent who supplies credit to households at a monthly interest rate of $r_{t}^{L} \%$ and accepts their deposits paying them an interest of $r_{t}^{D \%}$ per month. Instead of modelling the evolution of interest rates explicitly (e.g. reacting to a central bank's policy rate and borrowers' risk for the former and deposit demand for the latter), they are both set according to the actual figures of the applied historical scenario.

The key parameter that determines credit supply is DSTI ratio, defined as the sum of interest payments plus amortisations divided by the borrower's monthly income. Given that accurate data on the applied level of DSTI ratio by the banking sector for consumer loans are not publicly available, its values are calibrated based on a combination of data approximating its evolution and the resulting match of simulated to the realized series of credit growth following the procedure described in detail in Appendix A. It should be noted that DSTI 
ratio reflects the effect of every constraint (e.g. regulatory requirements) that the bank might face and has an impact on credit supply, but is not explicitly incorporated in the model. Thus, it can be regarded as effective DSTI. However, given that the volume of consumer credit is, in general, significantly lower compared to other assets (i.e. mortgages) the effect of regulatory constraints is expected to play a minor part $^{8}$, while bank's risk tolerance is expected to be the major factor shaping the applied DSTI ratio.

\subsubsection{Credit market}

Solvent households (i.e. those who do service their loans) whose own income and deposits do not allow them to satisfy their desired consumption ask for consumer credit:

$$
L_{h, t}^{a s k}=C_{h, t}^{d}-\left(I_{h, t}+D_{h, t-1}\right)
$$

When considering granting a consumer loan the bank calculates the highest affordable monthly payment by the potential borrower based on their income and its own risk tolerance proxied by DSTI as follows:

$$
L P_{h, t}^{\max }=D S T I_{t} \cdot I_{h, t}
$$

Therefore, the maximum amount of credit that the bank will offer is:

$$
L_{h, t}^{\max }=\frac{L P_{h, t}^{\max } \cdot\left[1-\left(1+r_{t}^{L}\right)^{-m}\right]}{r_{t}^{L}}-B_{h, t}
$$

where $m$ is the maturity of the loan, measured in months, which is assumed to be the same for all consumer loans.

As can be seen from Equation (10), the bank takes into account in its calculation any outstanding debt $\left(B_{h, t}\right)$ that the household might have. In which case the bank consolidates the new with the pre-existing credit by extending the latter's maturity and charging the current interest rate, $r_{t}^{L}$, to the sum of the two.

A final condition that the bank takes into consideration when extending credit is the reserve ratio requirement. Under this condition, the bank can lend up to $(1-R)$ of its total deposits, with $0<R<1$ denoting the reserve ratio.

Based on the figures of desired and offered credit, a household decides on the loan size it will obtain according to the following rule:

$$
L_{h, t}= \begin{cases}L_{h, t}^{\max }, & L_{h, t}^{a s k} \geq L_{h, t}^{\max } \\ U\left(L_{h, t}^{a s k}, L_{h, t}^{\max }\right), & L_{h, t}^{a s k}<L_{h, t}^{\max }\end{cases}
$$

Thus, if the credit offered by the bank is less than what is asked, the household borrows as much as possible. Alternatively, it borrows a random amount

\footnotetext{
${ }^{8}$ Indeed, the earliest regulatory application of DSTI limits is in late 2011 in few EU jurisdictions, while in the majority of the cases where they are applied refer only to housing credit (European Systemic Risk Board, 2018).
} 
from a uniform distribution between $L_{h, t}^{a s k}$ and $L_{h, t}^{\max }$. Therefore, a household's outstanding debt evolves as:

$$
B_{h, t}=B_{h, t-1}+L_{h, t}
$$

with the associated monthly payment being:

$$
L P_{h, t}=\frac{B_{h, t} \cdot r_{t}^{L}}{1-\left(1+r_{t}^{L}\right)^{-m}}
$$

It should be noted that all loans are of the fixed-payment type.

\subsubsection{Labour market}

The labour market is completely data-driven. Households' income growth follows the specific path of the historical scenario applied. As a simplifying assumption and in the absence of more specific data on income evolution, the scenario implied growth rate is assumed to affect all households uniformly, regardless of their position in the income distribution. ${ }^{9}$ In case unemployment rises by $x \%$, a randomly chosen set -of the appropriate size- of employed households becomes unemployed and instead of its monthly income, receives an unemployment dole from the government. ${ }^{10}$ If unemployment declines by $x \%$, a randomly chosen set -of the appropriate size- of unemployed households returns to employment receiving a random monthly income between the unemployment benefit and the median income of that period.

\section{Simulation results}

\section{$3.1 \quad$ Input data}

The injection of historical data into the ABM helps simplifying its structure by fixing the effect of non-modelled agents to the actual scenario, ${ }^{11}$ while at the same time allows to isolate and study the impact of few, selected variables. An extra benefit of keeping the simulation close to real data is that model validation goes beyond matching stylized facts to assessing how well the artificial time series fit the historical ones. Thus, in the baseline specification where all parameters are set to match the actual scenario, validating the model provides a clear-cut test of the suitability of the implemented rules and interactions to reproduce real-world phenomena.

\footnotetext{
${ }^{9}$ Therefore the results of this study can be seen as a benchmark in case income evolves homogeneously across its distribution. Of course differential growth among income percentiles is expected to reinforce (reduce) inequality and its effects, i.e. in case lower (upper) percentiles' income declines faster or upper (lower) percentiles' income increases more rapidly than their distributional counterparts.

${ }^{10}$ Similarly to income growth, unemployment growth is assumed to affect households in a random way, irrespective of their level of income.

${ }^{11}$ To the extent possible, conditional on data availability.
} 
Input data can be divided in two categories. The first includes those which are updated at every time step during the simulation and represent the historical scenario that the artificial economy follows. The second contains data which are used to calibrate the ABM and are mainly used to initialize it, such as income distribution parameters and the level of unemployment benefit. A special case which traverses both categories is DSTI. Its evolution enters the simulation exogenously but its initial values are calibrated to match the actual consumer credit series.

\subsubsection{Scenario data}

The time step of the simulation corresponds to one month, hence monthly historical data are used wherever possible. In case data at the desired frequency are missing, the closest available (i.e. quarterly) is transformed to monthly by cubic natural spline interpolation and used instead.

An important challenge encountered is the absence of publicly available, monthly data on household net disposable income (NDI) for EU countries. The highest available frequency is quarterly, provided by Eurostat. However, the series which extended sufficiently back in the past (as early as 2001q1 for almost all EU countries and even since 1995q1 for the majority of them) is discontinued with the last recorded observation being in $2014 \mathrm{q} 1 .{ }^{12}$ To overcome this issue, data for wages \& salaries are used as a proxy for NDI. Since the evolution of the two series may not necessarily coincide, only the cases where they exhibit a high degree of similarity are used as input in the subsequent simulation.

The comparison between available data on real $\mathrm{NDI}^{13}$ and real wages \& salaries reveals that the two series exhibit sufficiently similar patterns in four EU countries. Figure 1 and Figure 2 display their evolution in levels and annual growth rates respectively. It should be mentioned that nominal series are converted to real ones using the GDP deflator.

\footnotetext{
${ }^{12}$ The respective series could be found in Eurostat's dataset under the code ei_naia_q. It has been discontinued and removed from dissemination as it was part of the old data collection according to ESA95.

${ }^{13}$ The discontinued dataset on NDI covers 15 EU countries.
} 
EE

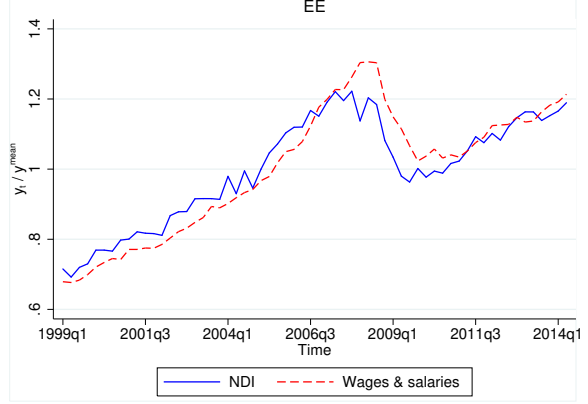

SI

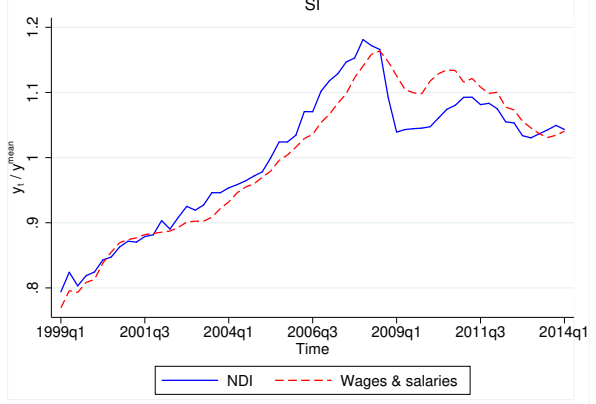

LT

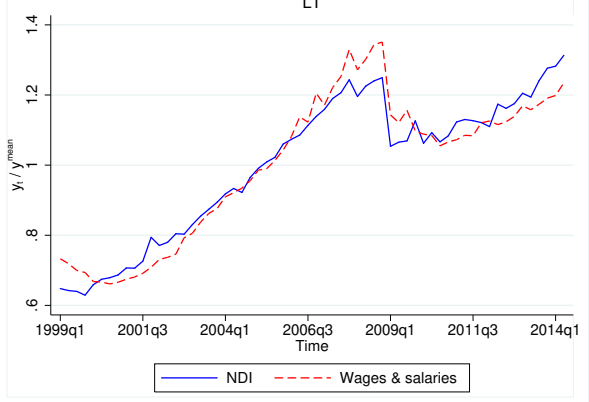

UK

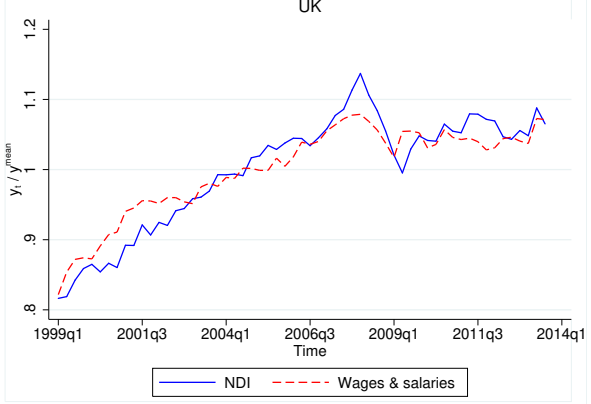

Figure 1: Comparison between the levels of NDI and wages \& salaries.

In order to facilitate comparison, original level data in Figure 1 are divided by their sample means $\left(y_{t} / y^{\text {mean }}\right)$. As is evident, the series in all four countries are adequately close. Some occasional mismatches are mostly associated with the global financial crisis of 2008 and its aftermath. In particular, in Slovenia (SI) and Great Britain (UK) NDI dropped more sharply than wages \& salaries, while the opposite is true for Lithuania (LT). In Estonia (EE), the two series move in a highly synchronized manner. These differences are expected to have little impact on the results. 
EE

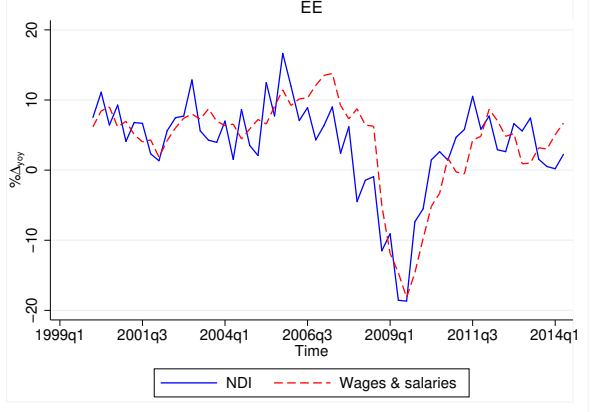

SI

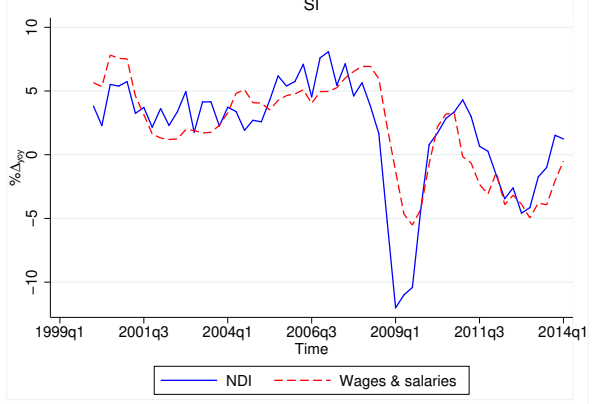

LT

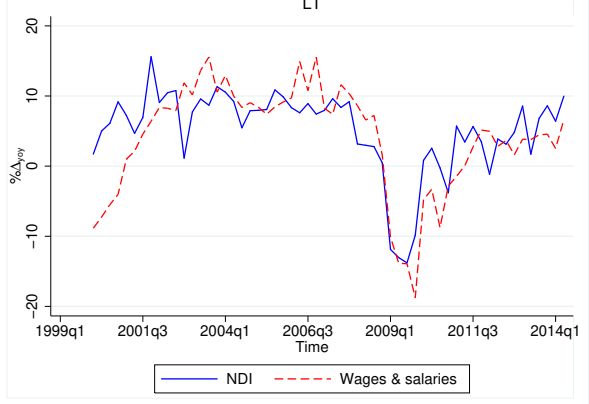

UK

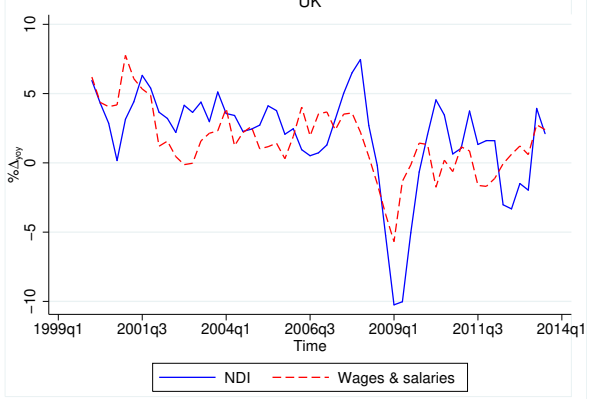

Figure 2: Comparison between annual growth rates of NDI and wages \& salaries.

The annual growth $\left(\% \Delta_{y o y}\right)$ of NDI and wages \& salaries in Figure 2 offers a complementary view on the findings of Figure 1. Estonian data almost overlap over the whole period whereas for Slovenia and Great Britain NDI's decline during the crisis was almost twice as deep compared to that of wages \& salaries. On the contrary, in Lithuania the latter decreased more than the former in 2009q1. A general pattern is that, apart from a short period after the crisis, the two series undergo similar changes within every country. From an intracountry perspective, Estonian and Lithuanian data (first row in both Figure 1 and Figure 2) exhibit a single dip located in late 2008 - early 2009 and recover or at least stabilize after 2011, whereas Slovenian and British data display a second period of negative growth around 2013. In Table 1 are reported three measures which provide a quantitative assessment of the distance and the co-movement between NDI and wages \& salaries. 
Table 1: Distance and similarity measures between NDI and wages \& salaries.

\begin{tabular}{ccccc} 
Country & Transformation & MAE & RMSE & Correlation \\
\hline \hline \multirow{2}{*}{ EE } & $y_{t} / y^{\text {mean }}$ & 0.045 & 0.056 & 0.948 \\
& $\% \Delta_{\text {yoy }}$ & 3.783 & 4.541 & 0.528 \\
\multirow{2}{*}{ LT } & $y_{t} / y^{\text {mean }}$ & 0.040 & 0.050 & 0.948 \\
& $\% \Delta_{\text {yoy }}$ & 3.955 & 5.179 & 0.639 \\
\multirow{2}{*}{ SI } & $y_{t} / y^{\text {mean }}$ & 0.026 & 0.033 & 0.926 \\
& $\% \Delta_{\text {yoy }}$ & 2.089 & 2.837 & 0.767 \\
\multirow{2}{*}{ UK } & $y_{t} / y^{\text {mean }}$ & 0.022 & 0.027 & 0.925 \\
& $\% \Delta_{\text {yoy }}$ & 2.333 & 2.872 & 0.474 \\
\hline
\end{tabular}

The measures used to estimate the distance between the two series are the frequently employed Mean Absolute Error (MAE) and Root Mean Squared Error (RMSE). Moreover, their synchronicity is estimated using the (zero lag) cross-correlation. Results indicate that, on average, the two series exhibit small differences. Both in growth rates and levels (as a ratio of their historical average) their difference ranges from about $2 \%$ to $4 \%$. In addition, they display a high degree of synchronization. In levels, correlation is above $90 \%$ for every country, while in growth rates the lower bound is around $50 \%$ for Estonia and UK and above $75 \%$ for the case of Slovenia with Lithuania being in between.

Data for the average monthly unemployment rate, measured as a percentage of active population, are collected from Eurostat and directly used in the simulation.

Interest rate related data are available from the European Central Bank's Statistical Data Warehouse (SDW) and in particular its Monetary \& Financial Institutions Interest Rate Statistics database. Consumer credit interest rates are extracted from the respective series of credit for consumption and other lending, with maturity over 1 and up to 5 years, while for deposits is used the overnight interest rate for deposits from households and NPISH. Both series are recorded as the average interest rate through each month and are reported in percent per annum. Thus, the appropriate transformation is applied to convert them to monthly interest rates.

\subsubsection{Calibration data}

The data used for calibration are mostly associated with the initial distribution of income. These include minimum and average income as well as the Gini coefficient of income distribution at the beginning of the simulation period. For the latter, the UNU-WIDER World Income Inequality Database (WIID3.4) is an excellent source with detailed information from a variety of providers and 
with sufficient coverage both in time and from a cross-country perspective.

For the former two series are used proxies, both by Eurostat. As a proxy for minimum income are used monthly minimum wages ${ }^{14}$, while average income is approximated by mean monthly earnings extracted from the Structure of Earnings Survey. ${ }^{15}$

\subsubsection{DSTI data}

The case of DSTI ratio is special because there is no precise information available for its level neither in micro nor in aggregate data. However, an alternative is the BIS's debt service ratios statistics database. This source provides internationally consistent, country-specific quarterly data which " should correctly capture how the [DSTI] in a particular country changes over time, even if it does not necessarily accurately measure its level relative to what one could obtain from the correct micro data" (Drehmann et al., 2015, p. 91). Although this is an aggregate measure and likely different from the bank-level one based on borrower basis as already recognized, in this study is assumed that the evolution of the two is roughly similar and thus the former can be used to provide an adequate approximation of the latter.

Figure 3 shows the evolution of DSTI ratio for households and NPISHs for a sample of EU countries and the US.

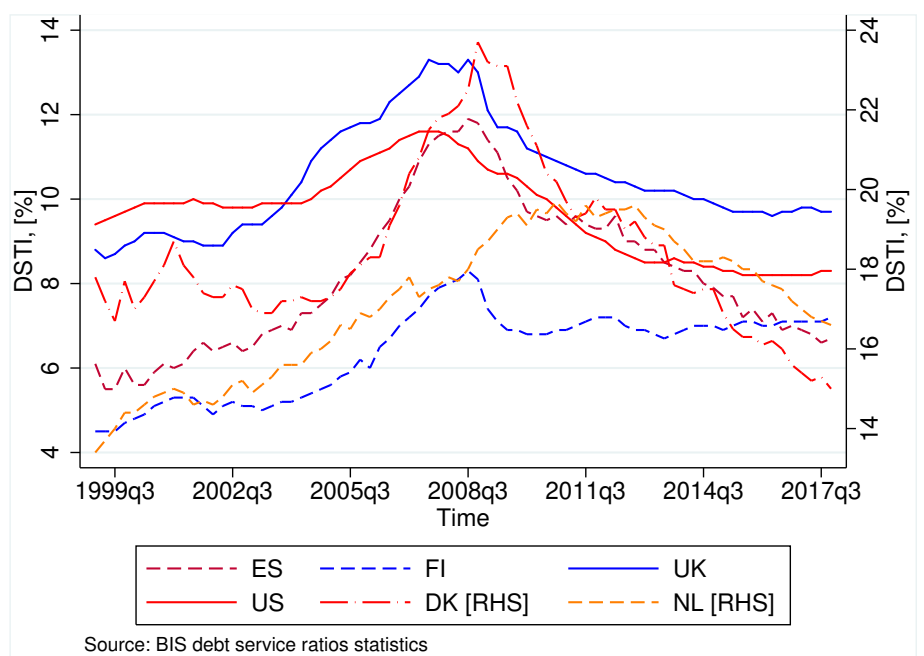

Figure 3: Evolution of DSTI ratio for households and NPISHs in a sample of countries.

Figure 3 shows that the aggregate DSTI ratios in the plotted countries share

\footnotetext{
${ }^{14}$ Eurostat dataset code: earn_mw_cur

${ }^{15}$ Eurostat dataset code: earn_ses_monthly
} 
a common evolution. A rapid growth roughly until the end of 2008 , followed by a decline with diverse degrees of severity.

Apart from the UK for which there are available data on DSTI, the selection of the remaining DSTI series to calibrate and match with the Estonian, Lithuanian and Slovenian historical macroeconomic scenario is based on the assumption that economic conditions in these countries resembled those in their larger European counterparts. Therefore, this should be reflected on an approximately comparable evolution of DSTI ratios. ${ }^{16}$ Data for the US are also included because, as can be seen in Figure 3, its DSTI shares a similar pattern with that of several European economies.

The calibration procedure is described in detail in Appendix A and consists of a grid-search to find which pair of \{initial DSTI, DSTI path minimizes the distance between the artificial and actual series of consumption and credit.

\subsection{Empirical validation}

In the empirical validation of the model its output is examined under a baseline setup where all variables and their paths are set according to a country-specific, historical scenario. The ultimate goal is to test its ability to produce close to real-world patterns and thus establish confidence in its results and use for policy simulations.

It should be emphasized that the degree of similarity between the implemented country-specific scenario and the real-world one is of paramount importance for the validation exercise. In that respect, the applied macroeconomic scenario for income and unemployment's evolution can be regarded to replicate the realized one in a sufficient manner, even under the assumption of that evolution being uniform across income distribution as described in subsection 2.3.5. However, the results from the DSTI calibration procedure described in Appendix A indicate that only in two countries (SI and UK) the calibrated DSTIs can satisfactorily reproduce the historical evolution of consumer credit. This suggests that the identified DSTI paths for these two cases are, potentially, a decent match of the actual ones. Therefore, for the validation exercise and the subsequent simulation experiments where DSTI is evolving through time the focus will be only on these two countries (SI and UK). The validation results for the other cases are reported in Appendix B, while for the simulations where DSTI is held fixed at a certain value, every country scenario is considered.

Income distribution parameters and scenario related variables are initialized according to the historical data as of January $2000^{17}$ which is the chosen origin of the simulation. The initial setup of the simulations is provided in Table 2 and Table 7.

\footnotetext{
${ }^{16}$ Of course country-specific factors are expected to affect the actual path of DSTI. Another source of divergence is the different evolution between consumer credit and mortgage DSTIs (see discussion in Appendix A for a detailed example). Thus, the final outcome depends on the degree of similarity between the actual and available data.

${ }^{17}$ Or the closest date available.
} 
Table 2: Initial setup of the simulation for SI and UK.

\begin{tabular}{ccc} 
Description & \multicolumn{2}{c}{ Country } \\
\hline \hline & SI & UK \\
\hline Average income & 1000 & 2430 \\
Minimum income & 350 & 950 \\
Gini coefficient of income distribution (\%) & 23 & 35 \\
Income distribution shape parameter $(\alpha)$ & 3.095 & 0.822 \\
Income distribution scale parameter $(\lambda)$ & 210 & 1800 \\
Unemployment rate (\%) & 7.1 & 5.8 \\
Consumer credit interest rate (\%) & 5.257 & 9.904 \\
Overnight deposit interest rate (\%) & 0.348 & 2.621 \\
DSTI (\%) & 50 & 56 \\
\hline
\end{tabular}

After a burn-in period of $N=170$ time steps, the country-specific historical scenario is input to the model. A description of the series used and their time periods is provided in Table 3 and Table 8.

Table 3: The range of the variables used in SI and UK historical scenarios.

\begin{tabular}{ccc} 
Variable & SI & UK \\
\hline \hline Wages \& salaries & $2000 \mathrm{q} 1-2018 \mathrm{q} 1$ & $2000 \mathrm{q} 1-2018 \mathrm{q} 1$ \\
Unemployment rate & $2000 \mathrm{~m} 1-2018 \mathrm{~m} 3$ & $2000 \mathrm{~m} 1-2018 \mathrm{~m} 3$ \\
Consumer credit interest rate & $2005 \mathrm{~m} 5-2018 \mathrm{~m} 3$ & $2004 \mathrm{~m} 1-2018 \mathrm{~m} 3$ \\
Overnight deposit interest rate & $2005 \mathrm{~m} 5-2018 \mathrm{~m} 3$ & $2004 \mathrm{~m} 1-2018 \mathrm{~m} 3$ \\
DSTI path & US & UK \\
\hline
\end{tabular}

The quarterly series for wages \& salaries are deflated using the GDP deflator and are converted to monthly frequency by spline interpolation. The processed wage series as well as unemployment rate are transformed into monthly growth rates. The missing data for interest rates for the first 3 to 5 years depending on country, are approximated with the average of the first 12 non-missing observations of each series. Finally, the DSTI path associated with each macroeconomic scenario is identified through the calibration process described in Appendix A. 
Besides scenario and initialization data which are country-specific, a set of parameters associated with agents' behaviour as well as to the model's setup is fixed across simulations and reported in Table 4.

Table 4: Fixed parameter values.

\begin{tabular}{ccc} 
Description & Parameter & Value \\
\hline \hline Number of households & $H$ & 1000 \\
Burn-in period & $N$ & 170 \\
Propensity to consume out of income & $\alpha_{y}$ & 0.65 \\
Propensity to consume out of deposits & $\alpha_{w}$ & 0.05 \\
WTR expectations extrapolation factor & $\omega_{w t r}$ & 0.4 \\
STR expectations extrapolation factor & $\omega_{s t r}$ & 1.3 \\
ADA expectations parameter & $\omega_{a d a}$ & 0.65 \\
Households' memory strength & $\eta$ & 0.7 \\
Households' expectations rule persistence & $\delta$ & 0.9 \\
Households' intensity of choice & $\beta$ & 0.4 \\
Loan maturity (in months) & $m$ & 60 \\
Reserve ratio & $R$ & 0.1 \\
\hline
\end{tabular}

Propensities to consume $\left(\alpha_{y}\right.$ and $\left.\alpha_{w}\right)$ are set to values commonly used by the literature (Godley and Lavoie, 2016; Assenza et al., 2015; Meijers et al., 2018, among others), while the HSM-related parameters are specified according to the figures identified by Anufriev and Hommes (2012a,b). The unemployment dole, coinciding with the subsistence consumption level, is assumed to be $80 \%$ of minimum income at each step of the simulation.

Each simulation is executed 100 times and the final results are summarized by the median over all runs. Median is preferred instead of average in order to avoid outlying values, especially when examining credit growth rates since they may initially assume very small values, thus yielding extraordinarily large growth rates. It should be mentioned that the comparison between artificial and historical data is performed against the original frequency and range of the latter. Hence, simulated data for consumption are summed over each quarter and observations from the simulated series for credit that lie outside the range of the actual data are discarded. 


\subsubsection{Validation with the Slovenian scenario}

The results for the Slovenian scenario, plotted in Figure 4, exhibit a decent match between artificial and historical data.
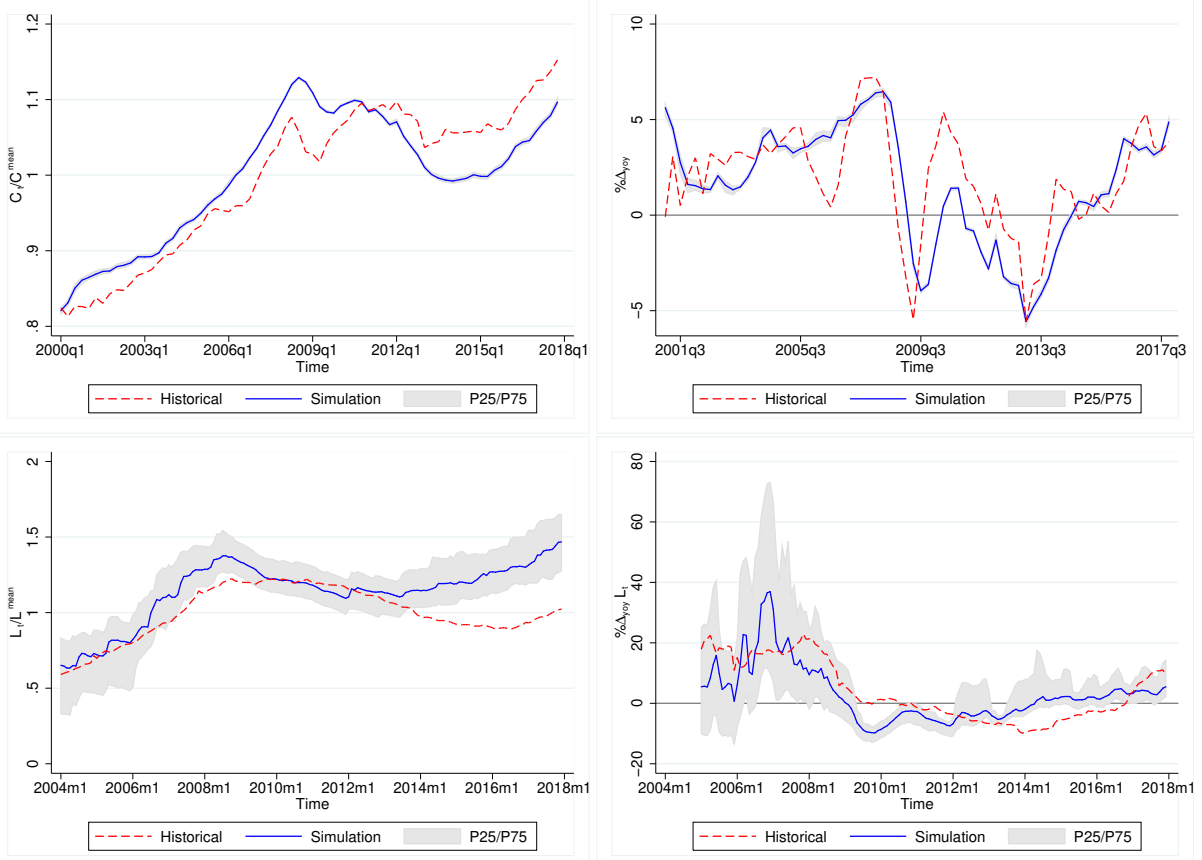

Figure 4: Baseline simulation results for the SI-specific scenario.

Firstly, simulated consumption displays a remarkable degree of similarity in terms of distance and synchronicity with the historical series. Moreover, simulated consumer credit data exhibit a high degree of resemblance to the evolution and magnitude of the historical series. This is indicated by the fact that, in addition to the median simulation being fairly close to the actual data, the latter lie between the first and third quartile (P25/P75) bands of the former for a large part of the simulation horizon. The divergence originates in 2013 when the artificial series begin to rise (Figure 4, bottom left pane), while the historical ones continue to decline up to 2016. This is associated with the financial difficulties faced by the domestic banking system at the time (Bank of Slovenia, 2013) resulting in a negative growth of consumer loans which only " moved into positive territory after six years [in 2016]." (Bank of Slovenia, 2016, p.44). Therefore, during this period, the assumed DSTI path used in the model is most likely more benign from what occurred in reality. However, after early 2017 the two series resume their co-movement indicating that from then on the assumed DSTI path is again an adequate approximation of the actual one.

The quantitative measures reported in Table 5 provide additional informa- 
tion on the findings of Figure 4.

Table 5: Distance and similarity measures between simulated and historical data for SI.

\begin{tabular}{ccccc} 
Variable & Transformation & MAE & RMSE & Correlation \\
\hline \hline \multirow{3}{*}{ Consumption } & $y_{t} / y^{\text {mean }}$ & 0.038 & 0.043 & 0.898 \\
& $\% \Delta_{\text {yoy }}$ & 1.801 & 2.270 & 0.710 \\
\multirow{2}{*}{ Credit } & $y_{t} / y^{\text {mean }}$ & 0.148 & 0.200 & 0.711 \\
& $\% \Delta_{\text {yoy }}$ & 6.222 & 7.375 & 0.708 \\
\hline
\end{tabular}

The distance between artificial and observed consumption is around $2 \%$ in growth rates and about $4 \%$ in rescaled levels. At the same time, correlation is high and ranges from $70 \%$ to almost $90 \%$. An important finding is that simulated consumer credit growth exhibits an average distance of $6 \%$ to $7 \%$ from the historical one while correlation remains at sufficiently high levels of about $70 \%$.

\subsubsection{Validation with the UK scenario}

The next scenario considered for validation purposes is the UK-specific one. Data for DSTI's path are available for this country ${ }^{18}$, which results in the closest emulation of consumer credit evolution generated by the model. The output is presented in Figure 5.

\footnotetext{
${ }^{18}$ Given the caveats discussed before, such as the essentially unknown levels of DSTI and potential differences between overall and consumer credit DSTI.
} 

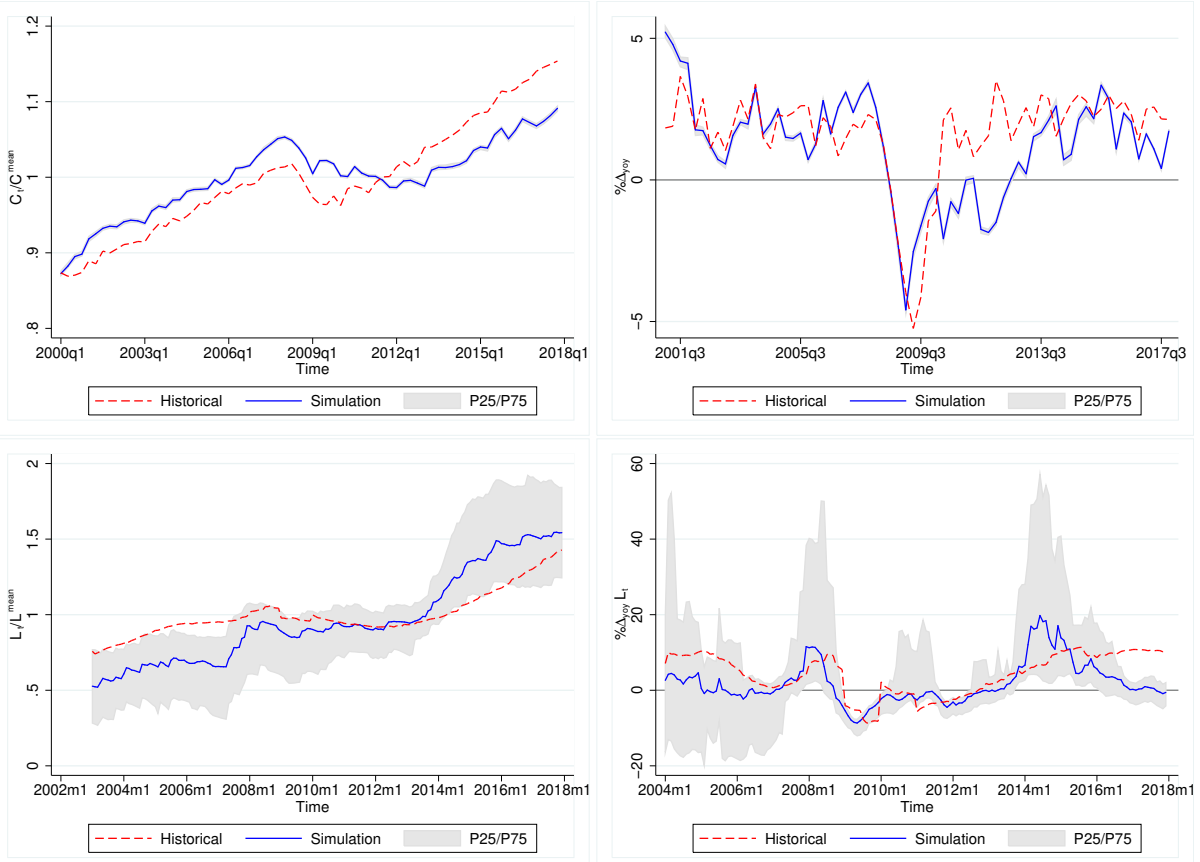

Figure 5: Baseline simulation results for the UK-specific scenario.

As seen in Figure 5, apart from simulated consumption series which show the, common among all scenarios (see also results in Appendix B), noteworthy similarity to the actual ones, simulated consumer credit exhibits the highest degree of closeness to the historical series from all scenarios examined. First and third quartile bands envelop the actual data for almost the entire simulation horizon both in levels and in growth rates. An obvious exception is observed towards the end of the simulation, approximately after early 2016, when simulated series begin to flatten and growth rates to decline whereas the actual ones show an upward trend (with the respective growth rates being on positive ground). It should be mentioned that to avoid distortions related to very low figures in the beginning of the simulation horizon, observations prior to December 2002 are discarded from the analysis.

Table 6 shows in a quantitative way the good fit between the artificial and historical series. 
Table 6: Distance and similarity measures between simulated and historical data for UK.

\begin{tabular}{ccccc} 
Variable & Transformation & MAE & RMSE & Correlation \\
\hline \hline \multirow{3}{*}{ Consumption } & $y_{t} / y^{\text {mean }}$ & 0.034 & 0.037 & 0.901 \\
& $\% \Delta_{\text {yoy }}$ & 1.191 & 1.621 & 0.606 \\
\multirow{2}{*}{ Credit } & $y_{t} / y^{\text {mean }}$ & 0.167 & 0.193 & 0.918 \\
& $\% \Delta_{\text {yoy }}$ & 4.774 & 5.929 & 0.538 \\
\hline
\end{tabular}

As expected, the results in Table 6 are the best among all scenarios examined. Simulated consumption displays the minimum distance and high correlation with actual data. Despite the fact that correlation between artificial and observed growth rates is relatively low compared to the other cases, it is still at the satisfactory level of about $60 \%$ while at the same time both MAE and RMSE are below $2 \%$. Results on consumer credit show a similar pattern; an average correlation accompanied by the lowest distance in growth rates and the highest correlation with comparable distance measures in rescaled levels.

Overall the validation exercise revealed three common patterns among all scenarios; first, there is a remarkably good fit between artificial and actual data on consumption. This indicates that the implemented consumption rule combined with data on disposable income can provide an appropriate approximation of aggregate consumption. Second, Q1/Q3 bands around median simulated consumption are very narrow. Since the stochastic element associated with consumption comes from consumer credit, this indicates that the latter is a small fraction of consumption. Finally, simulated consumer credit is adequately close to the observed data where available data for DSTI are a good approximation of the realized series. This enhances trust in the validity of the model to appropriately capture the underlying credit supply mechanism and reproduce its dynamics once reliable data are used as input.

\subsection{The role of expectations on credit demand}

A key element of the ABM under development is the implementation of the HSM for agents' expectations. The vast majority of macroeconomic ABMs is mainly endowing their agents with a single or, in some cases, two expectations heuristics. The most frequently used choices include naive expectations $\left(y_{t}^{e}=\right.$ $\left.y_{t-1}\right)$, an adaptive rule similar to that in Equation 4 or some form of trendextrapolative rule analogous to Equation 2. Other choices range from regressive techniques to rational expectations. The interested reader is referred to the excellent work of Franke and Westerhoff (2017) and references therein for a survey of modelling of animal spirits.

The only, to the best of the author's knowledge, macroeconomic ABM where 
the HSM is used, is by Dosi et al. (2017) where the authors find that expectations do not have a large effect on the dynamics of the economy.

However, credit demand in the present model depends heavily on income expectations and is essentially determined by households' forecast errors; optimistic households whose actual income is less than expected will likely ask for credit; on the contrary, pessimistic households will consume less, save more and deleverage. Therefore, given the central role that expectations play in the model, their effect on credit dynamics will be further examined.

All initialization parameters are set as reported in Table 2 with the exception of DSTI which is kept fixed at $100 \%$ over the whole simulation. This large value is chosen in order to enable the bank to accommodate practically any credit request, even if the associated monthly payment equals the borrower's income. Using each individual expectations heuristic alone, plus all four of them with the switching mechanism of the HSM, the evolution of credit for each macroeconomic scenario is examined and presented in Figure 6.
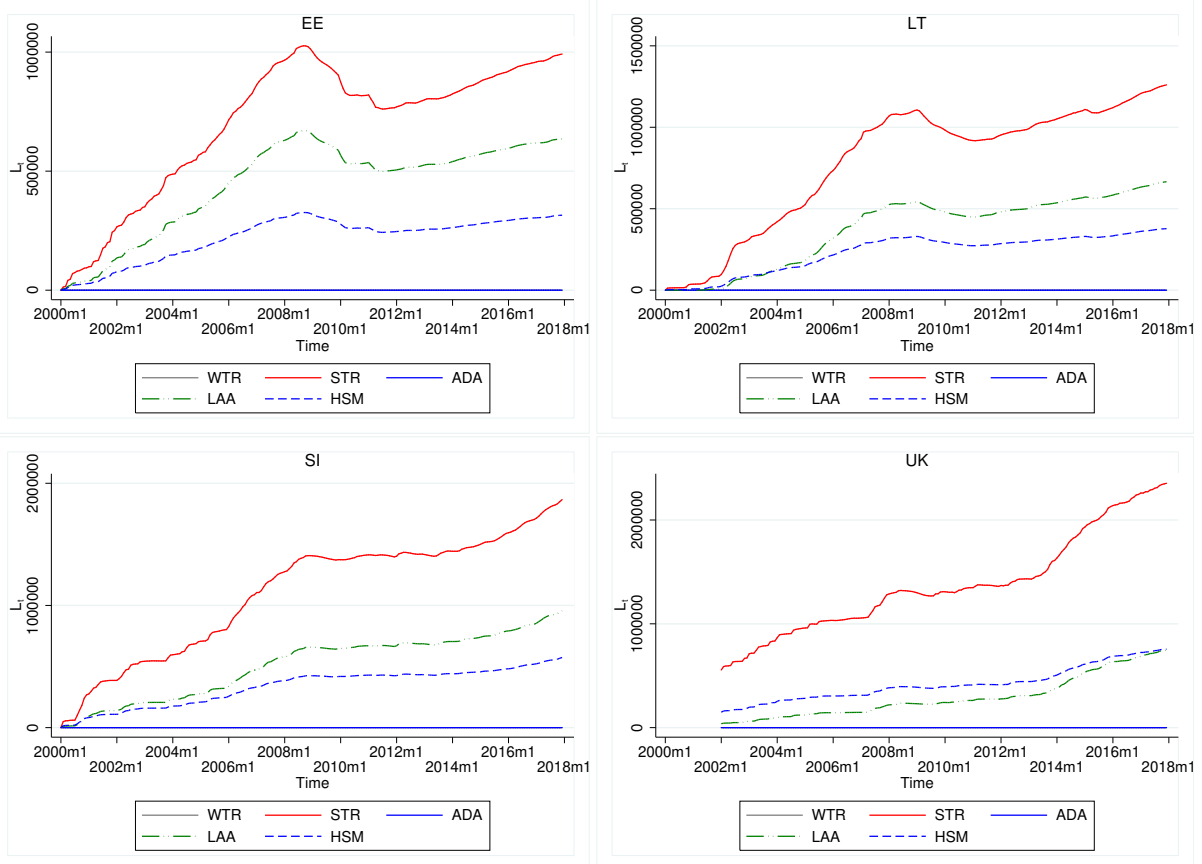

Figure 6: Outstanding credit evolution for different expectations heuristics.

In Figure 6 is plotted the mean outstanding credit in every time step over 100 simulations by expectations heuristic. The first observation is that, although credit growth rates are close for every heuristic -for a given country scenario- as demonstrated by the roughly similar patterns, the levels are markedly different. As one would anticipate, STR (red, solid line) is associated with more optimistic forecasts resulting in higher credit levels. The LAA rule (green, dash-dotted 
line), being a trend extrapolation one, also generates increased credit demand but not as high as the STR rule. Interestingly, mean ${ }^{19}$ outstanding credit is absent in the cases of WTR and ADA rules. This indicates that under these rules income expectations are very close to the realized figures or they are downwards biased. In the former case, the desired consumption demand from any small, optimistic income forecast can be met by deposit withdrawal. In case expectations are downwards biased, the actual income suffices to satisfy desired consumption therefore credit is not needed. Finally, the HSM being a changing mixture of all four rules, results in levels of credit which are influenced by the dominating heuristic and in any case lie between the polar cases of STR and WTR (or ADA). This is more evident in the case of the UK scenario ${ }^{20}$ where the simulation indicates that the LAA rule is heavily dominating, hence the results of the HSM are very close to the LAA's.

The differential effect of expectations heuristics on the level of credit raises the question whether this could also affect the size and evolution of non-performing loans ratio $\left(\mathrm{NPL}^{21}\right)$. The results for NPLs are extracted from the previous simulations for the heuristics that did lead to credit growth (STR, LAA and the HSM) and are plotted in Figure 7.

\footnotetext{
${ }^{19}$ Results are the same even up to the $75^{\text {th }}$ percentile of all simulation runs.

${ }^{20}$ Including initialization parameters. This is due to the fact that forecast errors for variables with sizable values in absolute terms (such as the average and minimum income related to the UK scenario) will be also large, thus influencing heuristic selection.

${ }^{21} \mathrm{NPL}$ ratio is defined as the share of loans which are past due by 6 or more consecutive months to total outstanding credit.
} 
EE

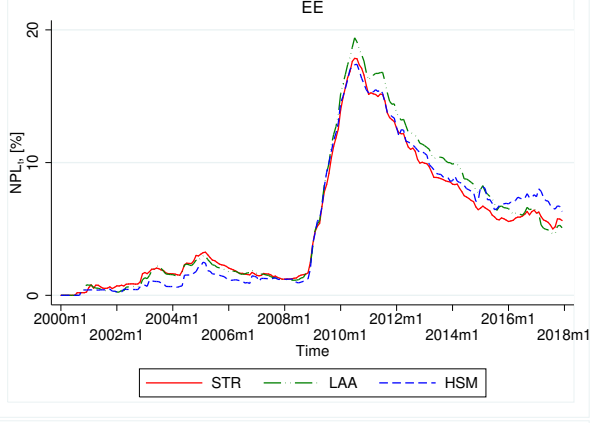

SI

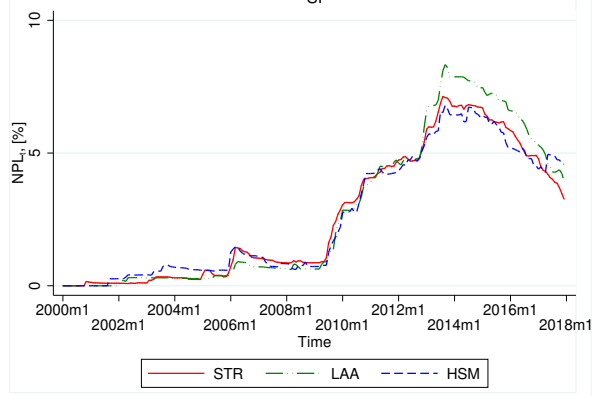

LT

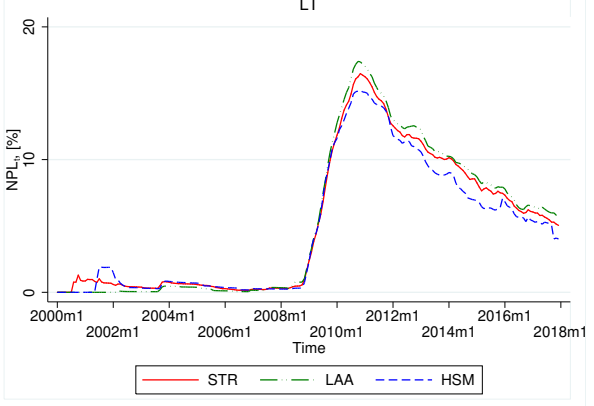

UK

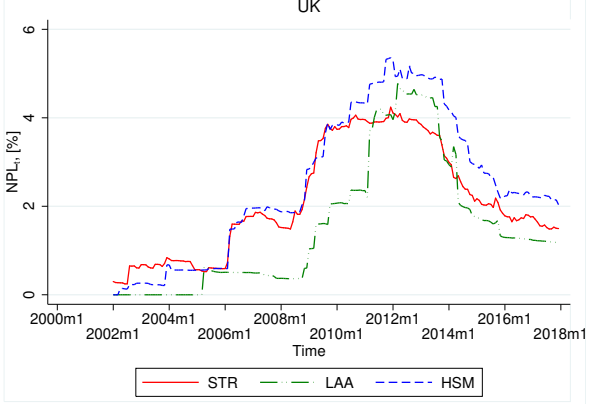

Figure 7: Non-performing loans ( $\geq 180$ days past due) ratio evolution for different expectations heuristics.

Figure 7 shows that average NPL evolution and size is almost identical among heuristics in three out of four cases. The exception is the UK-specific scenario where under the LAA rule average NPLs start to rise with an approximate 2year lag compared to the STR rule and the HSM. Apart from this discrepancy, the size as well as the evolution is comparable among all expectations heuristics.

The previous analysis suggests that expectations heuristics have differential and significant impact on the levels of provided credit, with some even resulting in its complete absence. Nevertheless, differences among those which do result in credit demand are not substantial neither in its growth rate nor in the size and evolution of NPLs. Consequently, taking also into account the experimental evidence by the respective literature, the HSM will be used throughout this study.

\subsection{Inequality, credit supply and macro-financial develop- ments}

In this part of the study the model is used to conduct several experiments to examine the impact of income inequality and credit supply -proxied by DSTIon aggregate consumption, outstanding credit and bank NPLs. To do that two modifications on the baseline scenario are applied; the first leaves DSTI at it's original setup and examines the effect of different initial inequality levels; the 
second fixes DSTI at certain values throughout the simulation and analyzes the impact of different initial levels of income inequality. The results from the experiments are discussed below.

\subsubsection{Evolving DSTI}

In the first experiment is examined the effect of initial income inequality on consumption, credit and NPLs. The simulation is executed with the only difference from the baseline settings being in the initial level of income inequality. For various income distribution Gini coefficients spanning from approximately $22 \%$ to about $38 \%$ the model is run 100 times using two of the scenarios examined (SI and UK) and the results over the whole simulation horizon are averaged ${ }^{22}$ and reported in Figure 8 to Figure 10. To facilitate comparison, results are benchmarked against the figure at the highest level of inequality. Hence, the vertical axis corresponds ${ }^{23}$ to $\% \Delta y_{\lambda}^{*}=100\left(\frac{y_{\lambda}}{y_{*}}-1\right)$, where $y=\{C, L\}, y_{\lambda}$ the value of variable $y$ at scale $\lambda$ and $y_{*}$ is the benchmark value of variable $y$. The two horizontal axes in the respective graphs denote the initial scale parameter, $\lambda$, of the $\Gamma(\alpha, 1 / \lambda)$ income distribution (bottom) or, equivalently, the corresponding Gini coefficient (top). In addition, the regression lines $\% \Delta y_{\lambda}^{*}=\beta_{y} \cdot$ Gini + constant $_{y}$ are drawn and the estimated $\beta_{y}$ coefficients with the corresponding statistical significance levels are reported.

The results for consumption are presented in Figure 8.
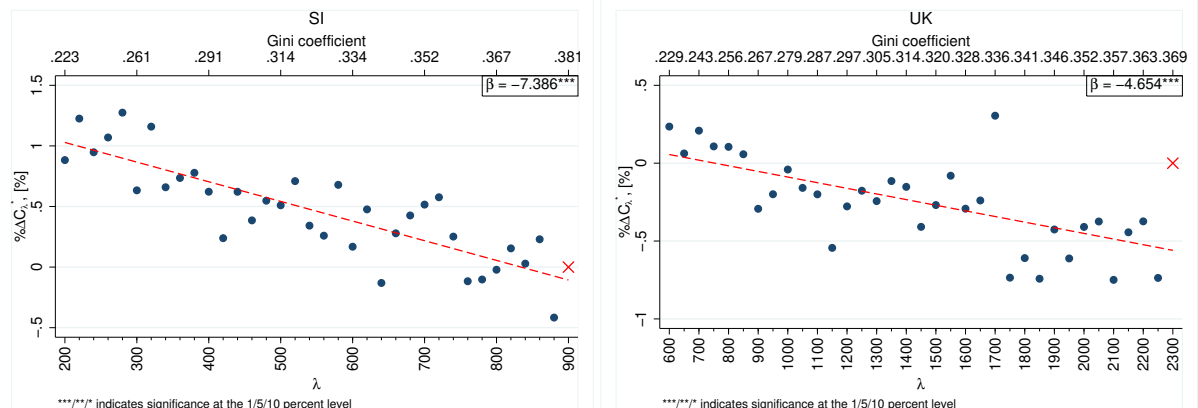

Figure 8: The effect of income inequality on average consumption. The red $\times$ denotes the benchmark value.

Figure 8 exhibits a clear, negative relationship between income inequality and average consumption for both scenarios. This is also manifested in the statistically significant coefficients of the respective regression lines which indicate that a $1 \%$ decrease in Gini coefficient of income distribution results in an approximate $0.04 \%$ to $0.07 \%$ increase in average consumption, depending on the

\footnotetext{
${ }^{22}$ Specifically, it's the whole period average of the average over the 100 runs.

${ }^{23}$ In the case of NPLs, the latter being already expressed as a ratio, the distance from the benchmark is simply $\Delta y_{\lambda}^{*}=y_{\lambda}-y_{*}$.
} 
scenario examined. The sign of the relationship is as expected. When income is more equally distributed, then a larger number of households have more funds available thus resulting in higher levels of consumption. On the contrary, when income is more concentrated, consumption cannot be supported by the few at the top of the distribution and therefore settles in lower average values. In the next subsection is examined whether considerably looser credit supply can mitigate the detrimental effect of inequality on consumption. Moving to consumer credit, Figure 9 reveals an interesting pattern.
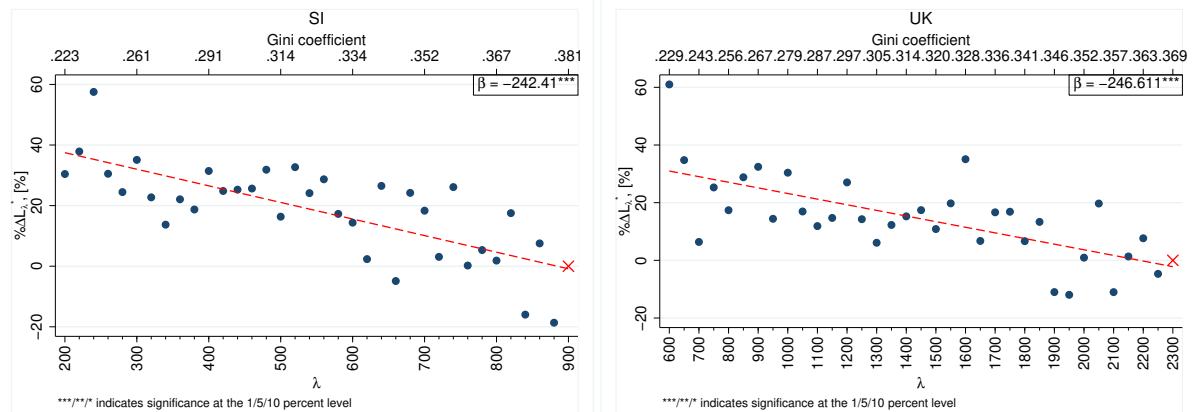

Figure 9: The effect of income inequality on average consumer credit. The red $\times$ denotes the benchmark value.

As seen in Figure 9, income inequality does affect the average volume of consumer credit. In particular, a $1 \%$ increase in the former (more precisely in income distribution's initial Gini coefficient) results in an approximate decrease of the latter by $2.4 \%$ as suggested by the respective regressions.

This result deserves further discussion given that various studies suggest a positive relationship between the two variables. The underlying rationale is associated with credit demand triggerred by households' desire to keep their consumption close to some external ("keeping up with the Joneses") or internal reference (own past consumption or "habit formation") level. Several, closely related, theories have been proposed to explain this behaviour such as the relevant income hypothesis (Duesenberry, 1967), the theory of expenditure cascades (Frank et al., 2014) or the need to sustain living standards by households at the bottom part of income distribution (Atkinson and Morelli, 2011). The work of Bazillier and Héricourt (2017) provides and a very comprehensive survey of the recent literature on the links between inequality, leverage and crises. Something that should be kept in mind is, however, that the aforementioned theories assume that households' access to credit is unrestricted by their income or risk.

An additional challenge is posed by the empirical study of the relationship between inequality and household leverage. While the measure of credit implied by the theories above is household credit -and in particular consumer credit- the majority of empirical studies use some aggregate measure of credit in the economy, including that to firms, which might be unrelated to inequality. This could 
affect the results, obscuring the potential underlying causal relationship. Even in the best case where household credit comprising of mortgages and consumer loans is considered, the different dynamics of the two components might have substantial impact on the results obtained and their interpretation. Indeed, data from Jordà et al. (2015) show that the trends and levels of the two types of credit are noticeably different in 17 countries $^{24}$, resulting in a $20 \%$ difference as a share of GDP around 2012. The possibly different mechanism associated with housing credit as opposed to consumer credit might imply a different explanation for credit growth than the need of low income households supporting their living standards (Bazillier and Héricourt, 2014). In fact, Coibion et al. (2014) using household level data reject the "keeping up with the Joneses" hypothesis, i.e. the demand-side explanation of credit growth and find a negative relation between inequality and household debt.

The pattern observed in Figure 9 is also associated with the supply-side of credit. The mechanism works through the adequately high income being held by a large number of households. This configuration results in more credit being considered as affordable by the banking sector (i.e. supported by the potential borrowers' income) for a given $\mathrm{DSTI}^{25}$ and therefore being granted once it is asked for, assuming that demand remains roughly the same under different inequality regimes ${ }^{26}$. Another key driver of this result is households' assumed consumption function in Equation 1. Since habit formation or comparison with some external reference level are not explicitly considered, desired consumption -and by extension consumer credit demand- is driven by income expectations. Nevertheless, once credit demand is expressed it is for the bank to decide how much to lend according to its DSTI level. Hence, households exceeding the bank's risk tolerance will be rationed and credit supply effectively limited. Finally, results for NPLs are shown in Figure 10.
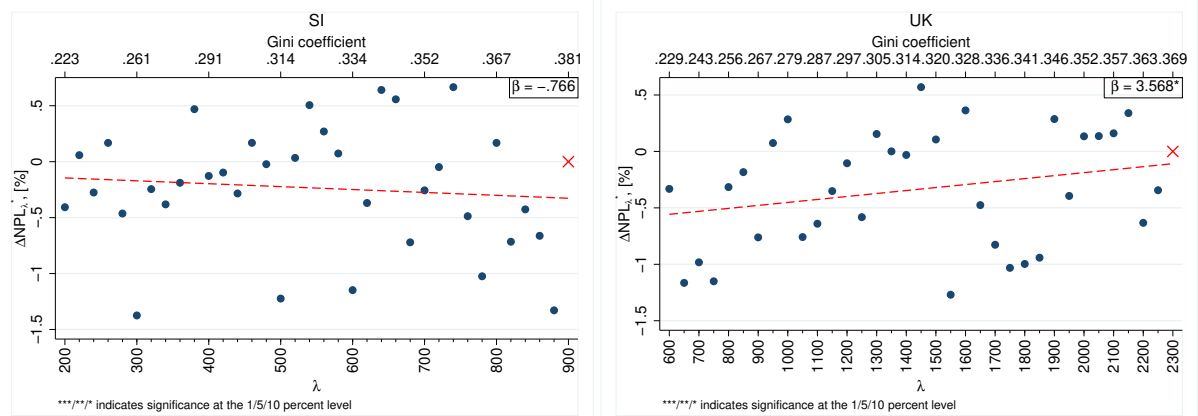

Figure 10: The effect of income inequality on average NPLs. The red $\times$ denotes the benchmark value.

\footnotetext{
${ }^{24}$ Especially in the period after early 2000s, which is the focus of the present study.

${ }^{25}$ And other supply-side related properties such as loan interest rates and maturities.

${ }^{26}$ Results from simulations which are available upon request suggest that indeed consumer credit demand is invariable across different initial income inequality levels.
} 
Figure 10 suggests that the relationship between income inequality and average NPLs is weak at best or possibly non-existent. In the UK-specific scenario (right graph in Figure 10), higher inequality is associated with higher NPLs, although the magnitude of the relationship is small and its statistical significance low. On the contrary, in the case of the SI-specific scenario NPLs seem to be independent from the level of income inequality, something which is reflected on the statistically insignificant (i.e. indistinguishable from zero) slope of the respective regression line. The main reason behind this result is the volume of consumer credit.

The volume of credit provided is primarily controlled by the interaction between the expectations-based demand and the DSTI-constrained supply. In general, the amount of consumer credit asked is small since income expectations are never that extraordinarily far from the realized values to render households' available financial resources inadequate to cover an important part of desired consumption. In addition, DSTI limits the maximum monthly loan installment of an indebted household at the level of $50 \%$ to $60 \%$ of its income, depending on the scenario applied (see Table 3). Finally, the debt assumed by a household stochastically ranges between the demanded and the maximum amount offered (see Equation 11). Thus, it is more probable that it will be lower than the upper value permitted by DSTI at any point in time. The interplay of these mechanisms results in the respective monthly installments being a small fraction of households' income, hence facilitating loan servicing even if income declines considerably. Therefore, the main driver of NPLs is unemployment, the latter being the reason for substantial income reduction, rendering debt unserviceable.

The stochastic, income-independent nature of unemployment shocks results in NPLs being unconnected with the levels of inequality. It is possible that differential unemployment growth across the distribution of income might influence the result depending on the direction and the degree of unemployment's impact. In case unemployment rises more among households at the bottom of income distribution than among those at the top, a stronger link between NPLs and inequality -conditional on the severity of this increase- could be expected. On the contrary, if the impact of unemployment is stronger among households at the top of income distribution -who, in general, do not resort to borrowing to meet their consumption needs- the relationship between NPLs and inequality is expected to be weak at best. The scarcity of exact data on unemployment's evolution by income percentile does not allow for the development of a more accurate historical scenario ${ }^{27}$, thus the baseline assumption of a uniform effect of unemployment will be applied, bearing in mind the caveats discussed above.

It should be reminded that NPLs are defined as the share of loans past due 6 months to total loans. Obviously, if instead of the ratio is considered the level

\footnotetext{
${ }^{27}$ Data from the international labour organization on the distribution of unemployment by education indicate that for Slovenia and the UK the largest share of unemployed persons have intermediate level of education. This pattern holds since 2000 in the former and 2005 in the latter. Although education level might give an indication about the distribution of unemployment by income, the three levels (basic, intermediate, advanced) considered make for a quite coarse distributional division with no clearly defined boundaries.
} 
of non-performing loans the sign of the relationship is clearly negative. Lower income inequality and its associated larger volumes of credit are more likely to result in higher amounts of non-performing obligations. In that respect, NPLs expressed as ratio is a more meaningful metric.

\subsubsection{Fixed DSTI}

In this experiment, besides the effect of initial income inequality, is also studied the effect of different DSTIs on consumption, credit and NPLs. In particular, DSTI ranges from $50 \%$ up to $80 \%$ and remains fixed throughout the simulation. Moreover, for each DSTI level the model is run 100 times with different initial income distribution Gini coefficients which span from about $22 \%$ to $38 \%$. The rest of the macroeconomic scenario remains at its baseline setup.

The average of every variable over the whole simulation per \{DSTI, initial Gini coefficient\} pair is plotted in Figure 11 to Figure 13. The benchmark against which the comparison is made, as well as the horizontal axes follow the same conventions as in the previous experiment. The vertical axis represents the various DSTI levels while the colour of each cell indicates their distance from the associated zero-level.
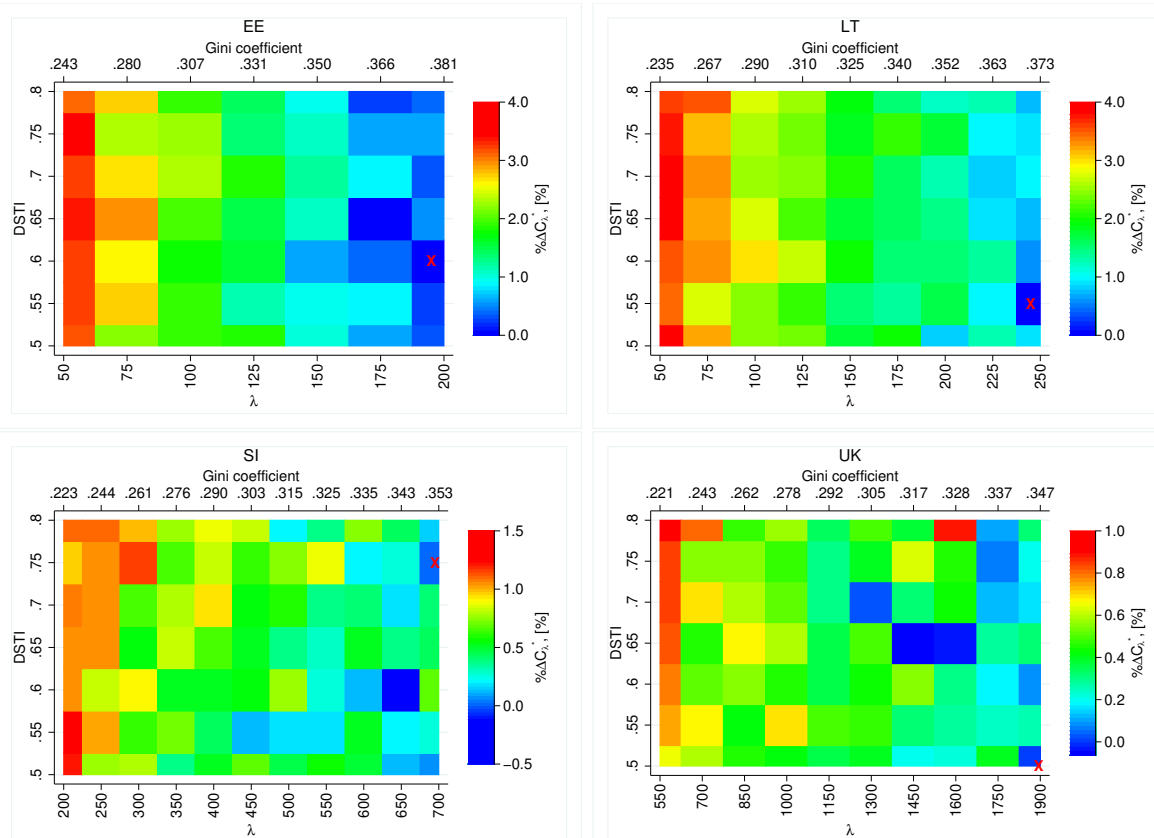

Figure 11: Average consumption per DSTI and initial income inequality level. The red $\times$ denotes the benchmark value.

Results in Figure 11 display an interesting pattern. For low levels of income inequality (Gini $\leq 25 \%$ to $27 \%$ approximately) average consumption is larger 
than the benchmark even for low levels of DSTI. This difference is more sizable in economies with lower absolute levels of minimum and average income, fluctuating around $4 \%$ as shown in the first row of Figure 11. As these distributional parameters increase, the magnitude of the effect declines to $1 \%-1.5 \%$ although the general pattern remains the same. As one moves to higher levels of inequality, consumption does not seem to be substantially supported by looser credit supply and settles to lower values. Finally, at the high inequality regions of the graphs consumption is evidently lower for any DSTI level as indicated by the more frequent cold-coloured patches in Figure 11.

Results for consumer credit are presented in Figure 12 and display a rather expected structure.
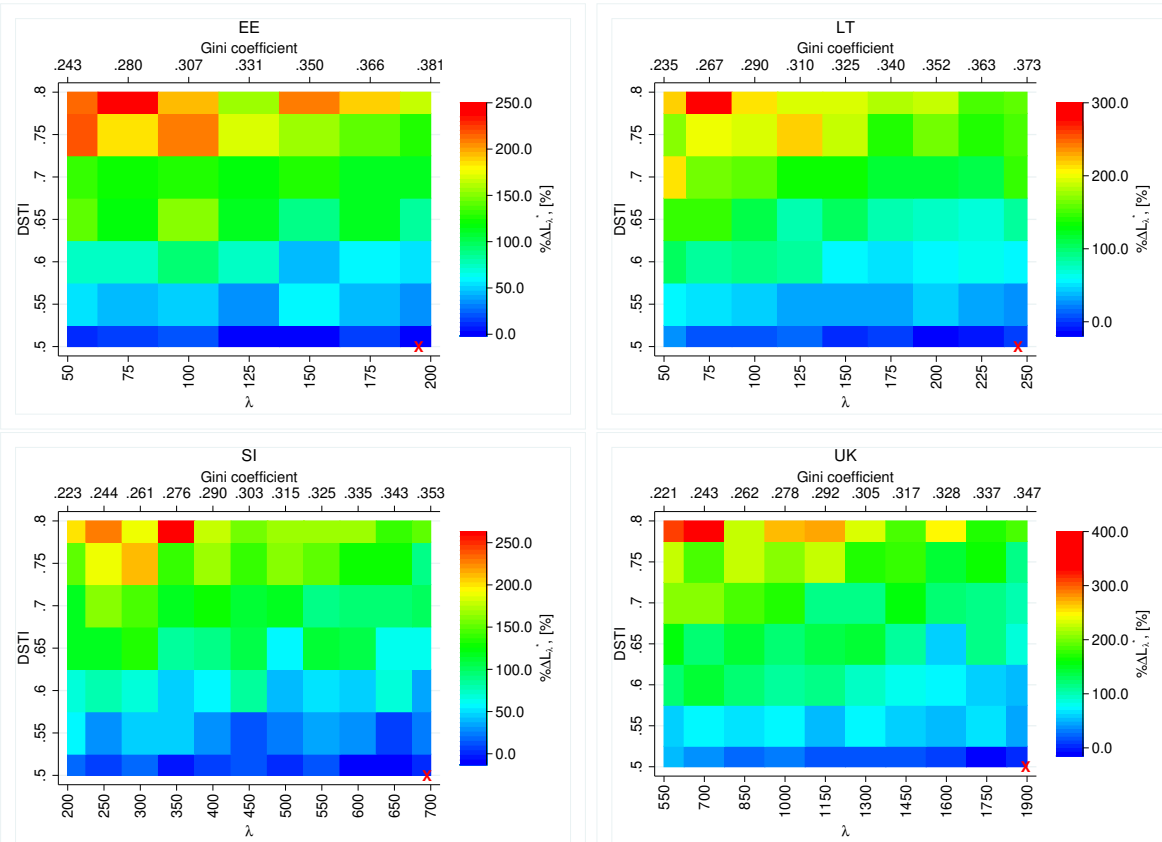

Figure 12: Average consumer credit per DSTI and initial income inequality level. The red $\times$ denotes the benchmark value.

In general, for any level of initial income inequality, an increase in DSTI levels is followed by an increase in the average volume of consumer credit. However, results indicate that income inequality does affect credit provision, with the sign of the relationship corroborating the findings of the previous experiment. For a given DSTI, average consumer credit is higher for smaller Gini coefficients and drops as the latter increases. It should be noted here that the considerably wide range of results is due to the small value of the benchmark, generated under the minimum DSTI examined.

Finally, the outcome of the experiment for NPLs is shown in Figure 13. 

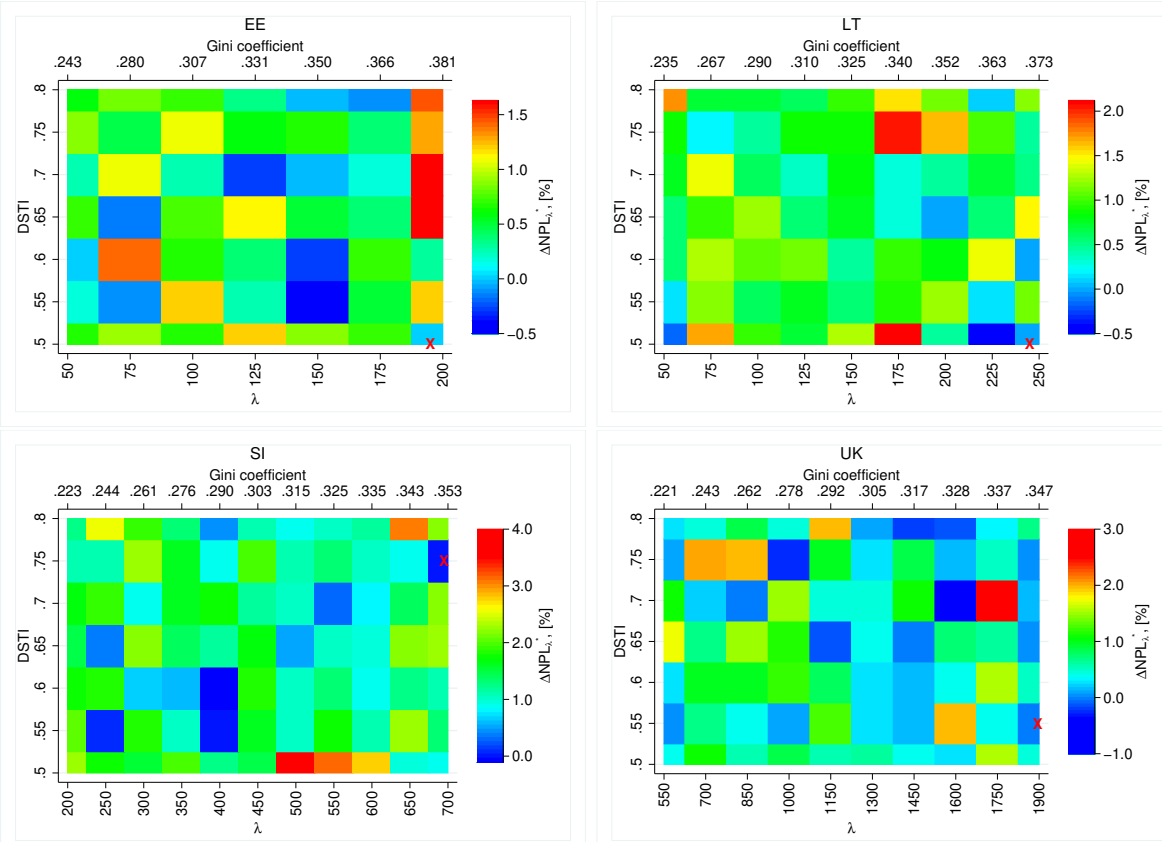

Figure 13: Average NPLs per DSTI and initial income inequality level. The red $\times$ denotes the benchmark value.

In line with the results of the experiment with evolving DSTI, Figure 13 suggests that there is no apparent link between the average level of NPLs and income inequality for any DSTI level. Cold and warm-coloured patches are alternating with no clear structure emerging within the range of DSTIs and Gini coefficients examined.

\section{Conclusions}

This study examined the effect of income inequality on consumption, credit and non-performing loans by the means of a simple, data-driven agent-based model.

For its development are used standard elements from the respective macroeconomic ABM literature, augmented with a heuristics switching model based on the findings from experimental studies on expectations formation. Overall, its structure is kept simple by replacing the actions of and interactions among some agents with the historical evolution of the associated series. This simplicity allows the model's output to be a markedly close replication of the actual data when input is accurate enough.

The good agreement of model's validation output with historical data suggests that, apart from studying the effects of income inequality, the model is suitable for policy simulation purposes. Under the baseline specification it can 
be readily used to provide scenario analyses examining the impact of macroprudential regulations (e.g. DSTI or consumer loan maturity limits) on consumption and credit growth, conditional on income and unemployment's evolution.

The experimental simulations performed with the model indicate that, in the long run, income inequality is negatively associated with both consumption and the volume of consumer credit. The former result is as expected. A more equal distribution of income implies that a larger number of households have more purchasing power available thus being able to maintain higher consumption levels. The latter result corroborates the findings of recent empirical studies which find a negative relationship between inequality and household debt. An interesting result is that the ratio of non-performing obligations as a share of total consumer credit seems to be independent of inequality. This is the outcome of the interplay between two mechanisms governing the volume of consumer credit; an expectations-based demand and a DSTI-constrained supply. These mechanisms result in serviceable debt levels even under significant income decreases for any inequality level. Obviously, this result should not be linked with the large volume of mortgages observed in many countries since the early 2000s and the associated non-performing obligations which cannot be studied under the current implementation of the model.

Future research aims at extending the model in several dimensions, while maintaining its close link with the actual data. A first step will be to include agents which in the current version are assumed to be exogenous such as firms or a more elaborate banking sector reacting to central bank's actions. Equipping the model with more active agents will also permit a more detailed description of various markets such as the labour market or the incorporation of additional ones such as the housing market. These extensions will allow to study the effect of implementing and the interactions among various economic policies thus assisting policy makers in supporting and promoting societies' well-being.

\section{References}

Allen, T. W. and Carroll, C. D. (2001). Individual learning about consumption. Macroeconomic Dynamics, 5(02):255-271.

Amaral, P. (2017). Monetary policy and inequality. Federal Reserve Bank of Cleveland Economic Commentary 2017-01.

Ampudia, M., Georgarakos, D., Slacalek, J., Tristani, O., Vermeulen, P., and Violante, G. (2018). Monetary policy and household inequality. ECB Working Paper, No. 2170.

Anufriev, M. and Hommes, C. (2012a). Evolution of market heuristics. The Knowledge Engineering Review, 27(2):255-271.

Anufriev, M. and Hommes, C. (2012b). Evolutionary selection of individual expectations and aggregate outcomes in asset pricing experiments. American Economic Journal: Microeconomics, 4(4):35-64. 
Assenza, T., Delli Gatti, D., and Grazzini, J. (2015). Emergent dynamics of a macroeconomic agent based model with capital and credit. Journal of Economic Dynamics and Control, 50:5-28.

Assenza, T., Heemeijer, P., Hommes, C. H., and Massaro, D. (2011). Individual expectations and aggregate macro behavior. De Nederlandsche Bank Working Paper No. 298.

Atkinson, A. B. and Morelli, S. (2011). Economic crises and inequality. Human Development Report Office (HDRO), No. HDRP 2011-06.

Bandourian, R., McDonald, J., and Turley, R. (2002). A comparison of parametric models of income distribution across countries and over time. LIS Working Paper Series, No. 305.

Bank of Slovenia (2013). Annual report. Technical report, Bank of Slovenia.

Bank of Slovenia (2016). Economic and financial developments, October. Technical report, Bank of Slovenia.

Bazillier, R. and Héricourt, J. (2014). The circular relationship between inequality, leverage, and financial crises: Intertwined mechanisms and competing evidence. Document de travail du CEPII, 1(22).

Bazillier, R. and Héricourt, J. (2017). The circular relationship between inequality, leverage, and financial crises. Journal of Economic Surveys, 31(2):463496.

Bordo, M. D. and Meissner, C. M. (2012). Does inequality lead to a financial crisis? Journal of International Money and Finance, 31(8):2147-2161.

Branch, W. A. (2004). The theory of rationally heterogeneous expectations: Evidence from survey data on inflation expectations. The Economic Journal, 114(497):592-621.

Brock, W. A. and Hommes, C. H. (1997). A rational route to randomness. Econometrica: Journal of the Econometric Society, pages 1059-1095.

Brock, W. A. and Hommes, C. H. (1998). Heterogeneous beliefs and routes to chaos in a simple asset pricing model. Journal of Economic Dynamics and Control, 22(8-9):1235-1274.

Caiani, A., Godin, A., Caverzasi, E., Gallegati, M., Kinsella, S., and Stiglitz, J. E. (2016). Agent based-stock flow consistent macroeconomics: Towards a benchmark model. Journal of Economic Dynamics and Control, 69:375-408.

Caiani, A., Russo, A., and Gallegati, M. (2017). Does inequality hamper innovation and growth? An AB-SFC analysis. Journal of Evolutionary Economics, pages $1-52$. 
Cardaci, A. and Saraceno, F. (2015). Inequality, financialisation and economic crisis: An agent-based model. Observatoire Francais des Conjonctures Economiques (OFCE).

Christen, M. and Morgan, R. M. (2005). Keeping up with the Joneses: Analyzing the effect of income inequality on consumer borrowing. Quantitative Marketing and Economics, 3(2):145-173.

Coibion, O., Gorodnichenko, Y., Kudlyak, M., and Mondragon, J. (2014). Does greater inequality lead to more household borrowing? New evidence from household data. Technical report, National Bureau of Economic Research (No. w19850).

Colciago, A., Samarina, A., and de Haan, J. (2018). Central bank policies and income and wealth inequality: A survey. De Nederlandsche Bank Working Paper No. 594 .

Dawid, H. and Delli Gatti, D. (2018). Agent-based macroeconomics. Handbook of Computational Economics, 4:63-156.

De Grauwe, P. and Macchiarelli, C. (2015). Animal spirits and credit cycles. Journal of Economic Dynamics and Control, 59:95-117.

Delli Gatti, D. and Desiderio, S. (2015). Monetary policy experiments in an agent-based model with financial frictions. Journal of Economic Interaction and Coordination, 10(2):265-286.

Delli Gatti, D., Desiderio, S., Gaffeo, E., Cirillo, P., and Gallegati, M. (2011). Macroeconomics from the bottom-up, volume 1. Springer Science \& Business Media.

Diks, C. and Van Der Weide, R. (2005). Herding, a-synchronous updating and heterogeneity in memory in a CBS. Journal of Economic Dynamics and Control, 29(4):741-763.

Dosi, G., Fagiolo, G., Napoletano, M., and Roventini, A. (2013). Income distribution, credit and fiscal policies in an agent-based keynesian model. Journal of Economic Dynamics and Control, 37(8):1598-1625.

Dosi, G., Fagiolo, G., Napoletano, M., Roventini, A., and Treibich, T. (2015). Fiscal and monetary policies in complex evolving economies. Journal of Economic Dynamics and Control, 52:166-189.

Dosi, G., Napoletano, M., Roventini, A., Stiglitz, J. E., and Treibich, T. (2017). Rational heuristics? Expectations and behaviors in evolving economies with heterogeneous interacting agents. LEM Working Paper Series 2017/31, Sant'Anna School of Advanced Studies.

Dosi, G., Pereira, M. C., Roventini, A., and Virgillito, M. E. (2016). The effects of labour market reforms upon unemployment and income inequalities: An agent-based model. Socio-Economic Review. 
Drehmann, M., Illes, A., Juselius, M., and Santos, M. (2015). How much income is used for debt payments? A new database for debt service ratios. BIS Quarterly Review, page 89.

Duesenberry, J. S. (1967). Income, saving, and the theory of consumer behavior, volume 180. Oxford University Press.

European Systemic Risk Board (2018). A review of macroprudential policy in the EU in 2017. Technical report, European Systemic Risk Board.

Fagiolo, G., Guerini, M., Lamperti, F., Moneta, A., and Roventini, A. (2017). Validation of agent-based models in economics and finance. LEM Working Paper Series.

Fagiolo, G., Moneta, A., and Windrum, P. (2007). A critical guide to empirical validation of agent-based models in economics: Methodologies, procedures, and open problems. Computational Economics, 30(3):195-226.

Fagiolo, G. and Roventini, A. (2017). Macroeconomic policy in dsge and agentbased models redux: New developments and challenges ahead. Journal of Artificial Societies \& Social Simulation, 20(1).

Frank, R. H., Levine, A. S., and Dijk, O. (2014). Expenditure cascades. Review of Behavioral Economics, 1(1-2):55-73.

Franke, R. and Westerhoff, F. (2017). Taking stock: A rigorous modelling of animal spirits in macroeconomics. Journal of Economic Surveys, 31(5):11521182 .

Geanakoplos, J., Axtell, R., Farmer, D. J., Howitt, P., Conlee, B., Goldstein, J., Hendrey, M., Palmer, N. M., and Yang, C.-Y. (2012). Getting at systemic risk via an agent-based model of the housing market. American Economic Review, 102(3):53-58.

Godley, W. and Lavoie, M. (2016). Monetary economics: An integrated approach to credit, money, income, production and wealth. Springer.

Gualdi, S., Tarzia, M., Zamponi, F., and Bouchaud, J.-P. (2015). Tipping points in macroeconomic agent-based models. Journal of Economic Dynamics and Control, 50:29-61.

Gurgone, A., Iori, G., and Jafarey, S. (2018). The effects of interbank networks on efficiency and stability in a macroeconomic agent-based model. Journal of Economic Dynamics and Control.

Haldane, A. G. and Turrell, A. E. (2018). Drawing on different disciplines: Macroeconomic agent-based models. Journal of Evolutionary Economics, pages $1-28$.

Hamill, L. and Gilbert, N. (2015). Agent-based modelling in economics. John Wiley \& Sons. 
Haruvy, E., Lahav, Y., and Noussair, C. N. (2007). Traders' expectations in asset markets: Experimental evidence. American Economic Review, 97(5):19011920.

Hassan, S., Pavón, J., Antunes, L., and Gilbert, N. (2010). Injecting data into agent-based simulation. In Simulating Interacting Agents and Social Phenomena, pages 177-191. Springer.

Hommes, C., Huang, H., and Wang, D. (2005). A robust rational route to randomness in a simple asset pricing model. Journal of Economic Dynamics and Control, 29(6):1043-1072.

Hommes, C., Sonnemans, J., Tuinstra, J., and van de Velden, H. (2004). Coordination of expectations in asset pricing experiments. Review of Financial Studies, 18(3):955-980.

Hommes, C., Sonnemans, J., Tuinstra, J., and van de Velden, H. (2008). Expectations and bubbles in asset pricing experiments. Journal of Economic Behavior \& Organization, 67(1):116-133.

Iacoviello, M. (2008). Household debt and income inequality, 1963-2003. Journal of Money, Credit and Banking, 40(5):929-965.

Jordà, Ò., Schularick, M., and Taylor, A. M. (2015). Betting the house. Journal of International Economics, 96:S2-S18.

Kumhof, M., Rancière, R., and Winant, P. (2015). Inequality, leverage, and crises. American Economic Review, 105(3):1217-45.

Mankiw, N. G., Reis, R., and Wolfers, J. (2003). Disagreement about inflation expectations. NBER Macroeconomics Annual, 18:209-248.

Meijers, H., Nomaler, Ö., and Verspagen, B. (2018). Demand, credit and macroeconomic dynamics. a micro simulation model. Journal of Evolutionary Economics, pages 1-28.

Modigliani, F. and Brumberg, R. (1954). Utility analysis and the consumption function: An interpretation of cross-section data. Franco Modigliani, 1:388436.

Palagi, E., Napoletano, M., Roventini, A., and Gaffard, J.-L. (2017). Inequality, redistributive policies and multiplier dynamics in an agent-based model with credit rationing. Italian Economic Journal, 3(3):367-387.

Perugini, C., Hölscher, J., and Collie, S. (2015). Inequality, credit and financial crises. Cambridge Journal of Economics, 40(1):227-257.

Pfajfar, D. and Santoro, E. (2010). Heterogeneity learning and information stickiness in inflation expectations. Journal of Economic Behavior 85 Organization, 75(3):426-444. 
Pfajfar, D. and Žakelj, B. (2016). Inflation expectations and monetary policy design: Evidence from the laboratory. Macroeconomic Dynamics, 22(04):10351075.

Piketty, T. and Saez, E. (2003). Income inequality in the United States, 19131998. The Quarterly Journal of Economics, 118(1):1-41.

Piketty, T. and Saez, E. (2006). The evolution of top incomes: A historical and international perspective. American Economic Review, 96(2):200-205.

Riccetti, L., Russo, A., and Gallegati, M. (2015). An agent based decentralized matching macroeconomic model. Journal of Economic Interaction and Coordination, 10(2):305-332.

Ricetti, L., Russo, A., and Gallegati, M. (2013). Unemployment benefits and financial leverage in an agent based macroeconomic model. Economics: The Open-Access, Open-Assessment E-Journal, 7(2013-42):1-44.

Russo, A., Riccetti, L., and Gallegati, M. (2016). Increasing inequality, consumer credit and financial fragility in an agent based macroeconomic model. Journal of Evolutionary Economics, 26(1):25-47.

Stonedahl, F. and Rand, W. (2014). When does simulated data match real data? In Advances in Computational Social Science, pages 297-313. Springer.

\section{A Calibration of initial DSTI and its evolution}

The fact that exact information about the level of DSTI and its path is not available poses a major challenge given the data-driven nature of the ABM under development. Although consumption is not significantly affected (as suggested by the narrow bands around simulated consumption series in Figure 4 and Figure 5), consumer credit strongly depends on DSTI levels (see e.g. Figure 12) and its evolution through time. In this section is described an attempt to overcome this issue by calibrating the level and path of DSTI using publicly available information.

The only source which provides internationally consistent, country-specific data on DSTI is the BIS's debt service ratios statistics database. This dataset has two desirable properties; its quarterly frequency is adequately high for transforming it to a satisfactorily realistic monthly interpolation and there are separate series by borrower type, including households and NPISHs. One caveat associated with the last property is that, even though the data refer to DSTI for credit provided to households and NPISHs, there could be significant differences by credit type; i.e. housing and consumer credit. Indeed, the case of the US where more detailed data exist from the Federal Reserve Board's Financial Obligations Ratios database presented in Figure 14 is illuminating. 


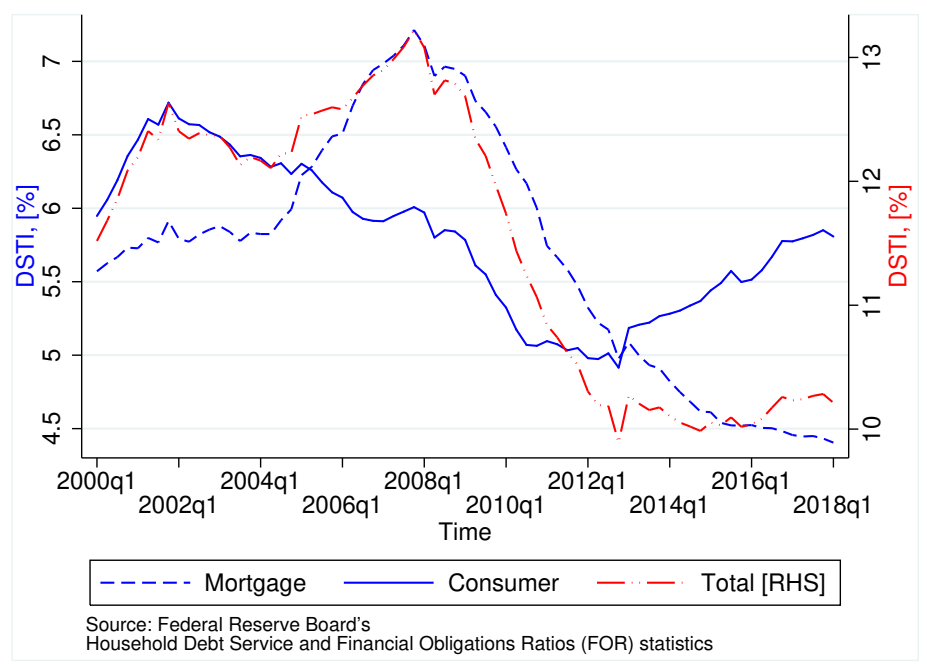

Figure 14: Household debt service payments and financial obligations as a percentage of disposable personal income for the US (seasonally adjusted).

As can be seen in Figure 14, up to approximately early-2002 the two components of total DSTI share a roughly common evolution. However, from then until 2008 their paths are strongly divergent with consumer credit DSTI declining while mortgage DSTI showing a sharp upward trend. Since 2008 and the emergence of the subprime crisis, mortgage DSTI decreases at a faster rate compared to consumer credit's and it currently seems to have stabilized around it's lowest figures reached in 2013. On the contrary, the latter shows a solid recovery from its 2013 bottom and now is close to its 2000 levels. Another important observation is that, for the most part, total DSTI's pattern (plotted in red, dash-dotted line in Figure 14) resembles more closely that of mortgage DSTI's. Thus, since in the BIS's database DSTI refers to total credit, this might result in discrepancies between simulated and historical data on consumer credit when inserted into the model.

Apart from the specific path, another important missing element is the level of DSTI. Data from the BIS " should correctly capture how the DSTI in a particular country changes over time, even if it does not necessarily accurately measure its level relative to what one could obtain from the correct micro data" (Drehmann et al., 2015, p. 91). Since the issue of disentangling the two DSTI components cannot be addressed, the subsequent procedure focuses on at least approximating the level and path of DSTI and associate it with the countryspecific macroeconomic scenarios examined.

The calibration process consists of a grid-search over a range of initial DSTI values combined with several growth rate paths for DSTI in order to find which combination yields the minimum distance and maximum similarity between simulated and actual series of consumer credit. 
The choice of initial DSTI range over which the grid-search is performed, is guided by the figures applied by the respective authorities as regulatory constraints on European banks. A recent report by the European Systemic Risk Board (European Systemic Risk Board, 2018) indicates that DSTI limits range between $40 \%$ to $80 \%$ of households' disposable income. These constraints mostly apply for housing credit but there are several occasions where similar values are considered for consumer credit. Therefore, a reasonable search range for initial DSTI values is between $40 \%$ to $60 \%$ considering that almost every DSTI path applied increases from 2000 until 2008. A step of $2 \%$ is used since it is fine enough to allow for a sufficiently dense examination while it is as coarse as needed to keep computational burden manageable.

The DSTI growth rate paths are calculated from the BIS series, after transforming them from quarterly into monthly frequency through cubic spline interpolation. Apart from the case of UK where country-specific data are available, the choice for the rest countries is based on the assumption that they should broadly exhibit a comparable evolution of DSTIs with their larger European counterparts due to roughly similar economic conditions. Thus, the DSTI growth rate paths examined are those from Denmark (DK), Spain (ES), Finland (FI), the Netherlands (NL), the UK (UK) and the US (US) plotted in Figure 3. The last one is included because it shares a similar pattern with that of many European economies.

The simulation is executed 100 times under the baseline parameter setup for each pair of \{initial DSTI, DSTI growth rate path\} resulting in 726 pairs per country. Next, the median of the rescaled levels and annual growth rates of consumer credit over all runs per pair is compared with the respective historical series. The measures for comparing the simulated with the observed data are the commonly used Mean Absolute Error (MAE), Root Mean Squared Error $(\mathrm{RMSE})^{28}$ and zero-lag cross-correlation (Stonedahl and Rand, 2014). Finally, the combination resulting in the minimum distance and maximum correlation is selected and added to the respective country's baseline macroeconomic scenario. In case results are not conclusive, a balanced choice is made taking into account performance in both rescaled levels and annual growth rates. In Figure 15 to Figure 18 are plotted the distance and correlation measures following from the described grid-search procedure.

\footnotetext{
${ }^{28}$ Also known as Manhattan and Euclidean distances respectively.
} 

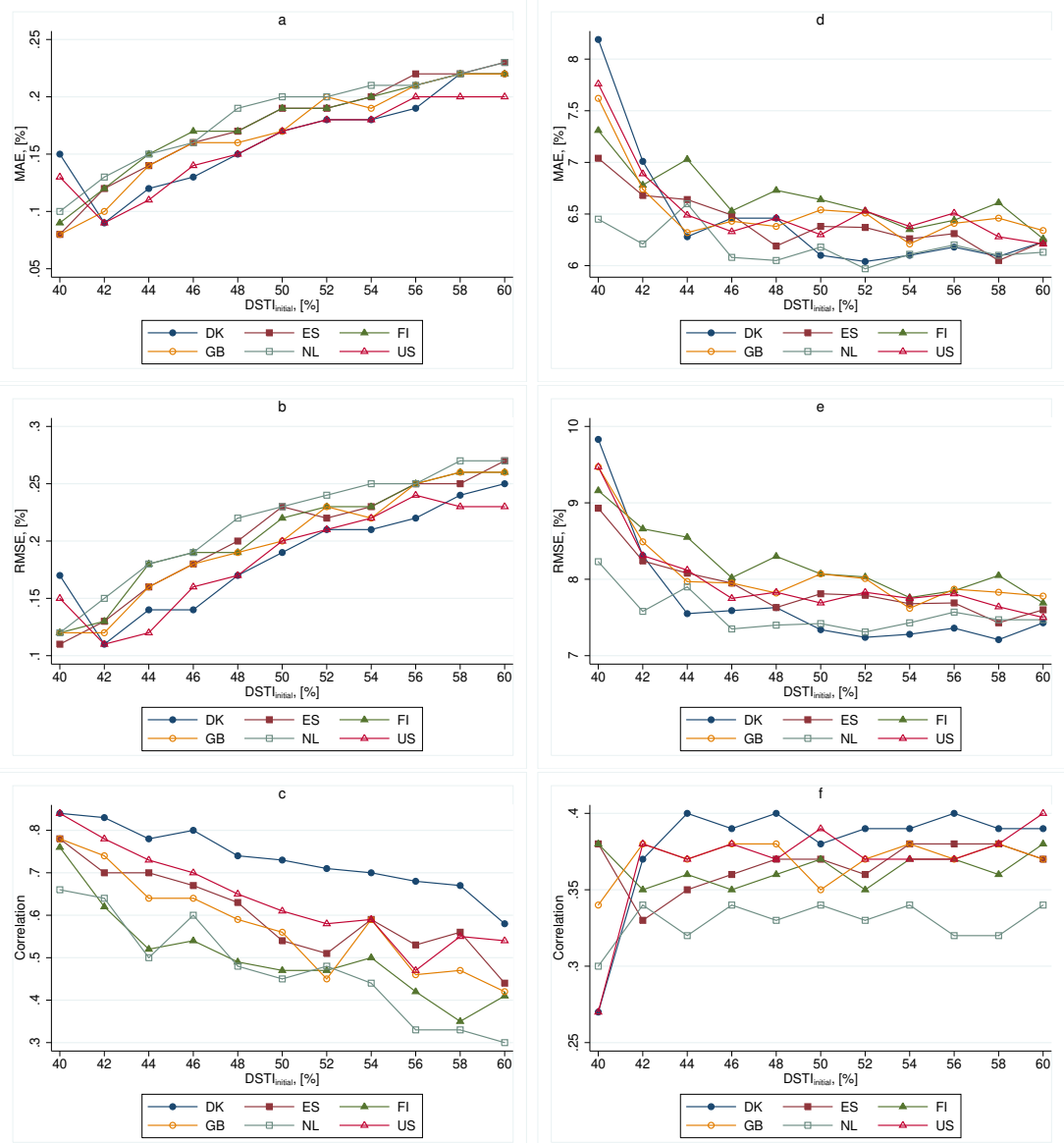

Figure 15: Calibration of initial DSTI and DSTI growth rate path for EE. Panels (a) to (c) correspond to the distance between simulated and historical consumer credit series in rescaled levels and (d) to (f) to annual growth rates.

The results for case of EE in Figure 15 indicate that possibly none of the DSTI paths examined is a good approximation of what actually occurred. On the one hand the best fit in rescaled series is observed for low initial DSTI levels, while the opposite holds for annual growth rates. One common feature seems to be that the DK scenario exhibits the best performance in both cases. Therefore, this is selected with the initial value set to $50 \%$ as trade-off between the two transformations. 

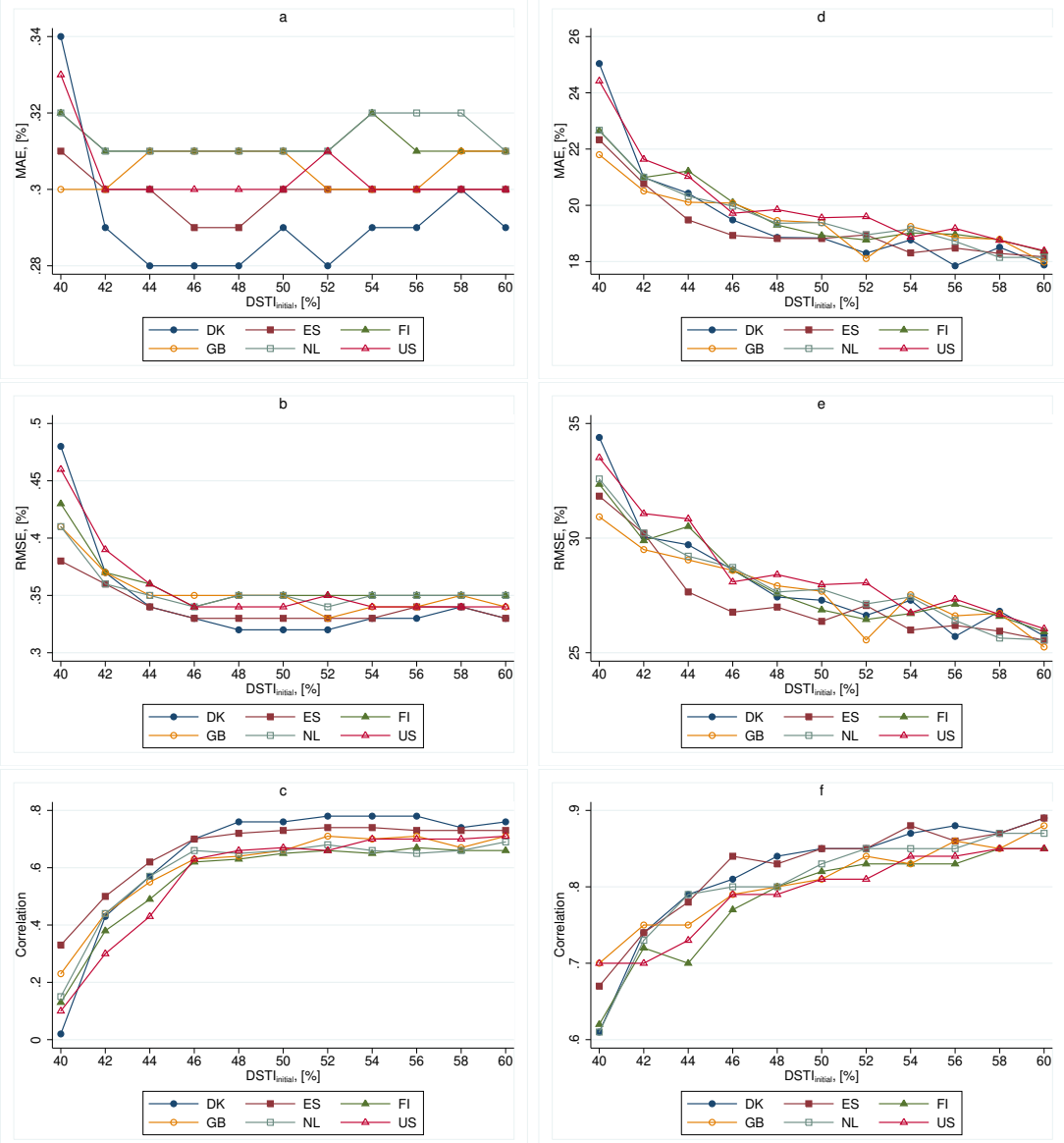

Figure 16: Calibration of initial DSTI and DSTI growth rate path for LT. Panels (a) to (c) correspond to the distance between simulated and historical consumer credit series in rescaled levels and (d) to (f) to annual growth rates.

In the case of LT the calibration results exhibit a uniform pattern; in both rescaled levels and annual growth rates distance is smaller for higher initial DSTIs and stabilizes for $D S T I_{\text {initial }} \geq 50 \%$. While all DSTI paths display comparable performances, the DK one seems to perform slightly better. For the choice of initial DSTI, the value of $52 \%$ is selected since results after that do not substantially improve. One noticeable fact is that distance measures are significantly larger in LT compared to other countries, especially in annual growth rates (around 3 to 4 times higher). This suggests that, as in EE, also in this case the applied DSTI paths are likely not a good approximation of the realized series. 

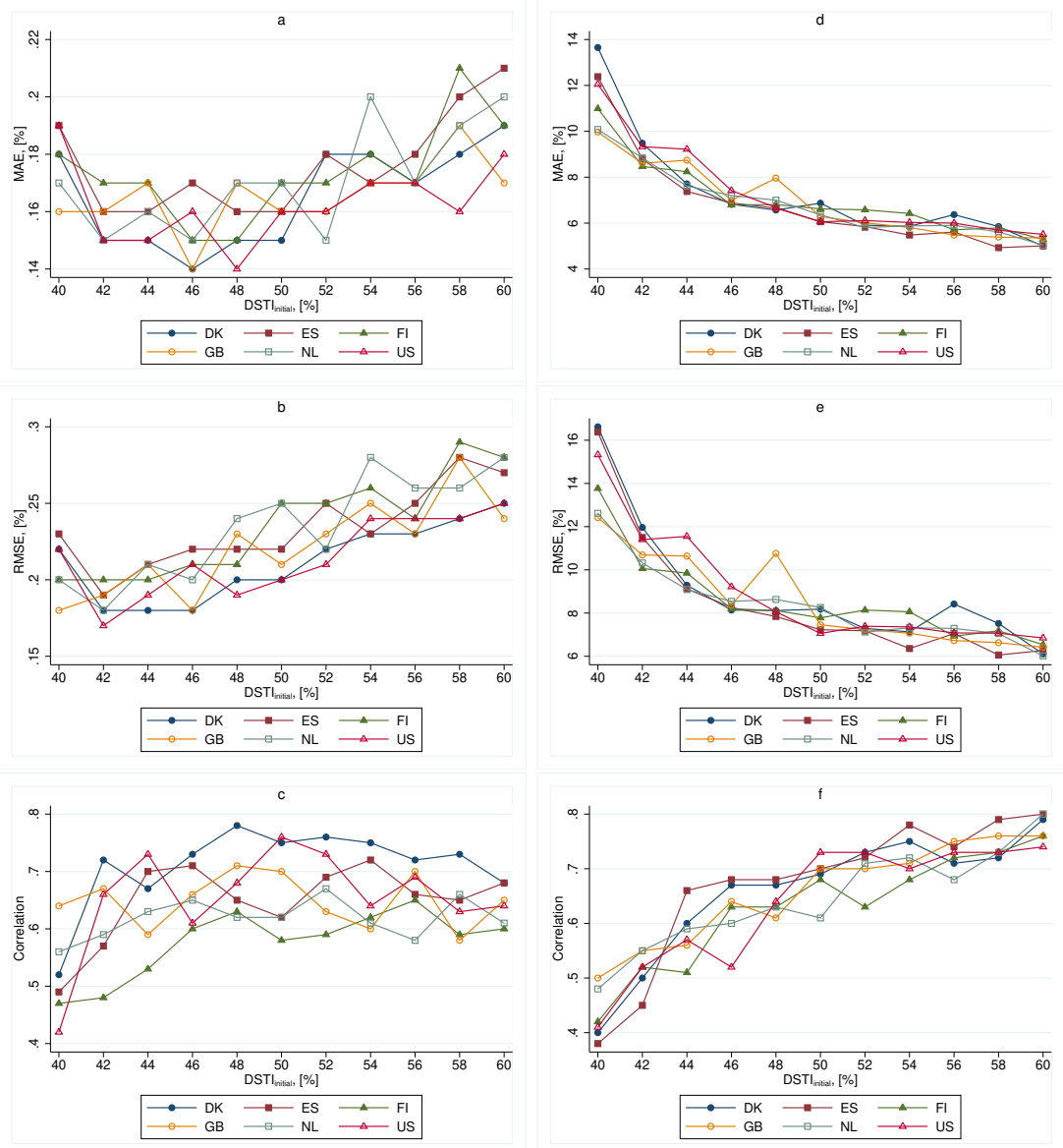

Figure 17: Calibration of initial DSTI and DSTI growth rate path for SI. Panels (a) to (c) correspond to the distance between simulated and historical consumer credit series in rescaled levels and (d) to (f) to annual growth rates.

Results for SI in Figure 17 display two patterns. In rescaled levels performance improves roughly up to $D S T I_{\text {initial }}=50 \%$ and then deteriorates, while in growth rates it continues monotonically as initial DSTI increases (albeit at a declining rate). The scenarios which seem to outperform the rest are the DK and the US one with the latter being marginally better. Hence the initial level of DSTI is set to $50 \%$ and the selected scenario is the US-specific. It should be mentioned that anecdotal discussions with supervisors suggest that indeed the path of the Slovenian banking system's DSTI has an inverted U shape and currently its levels are considerably lower compared to the pre-crisis status. 

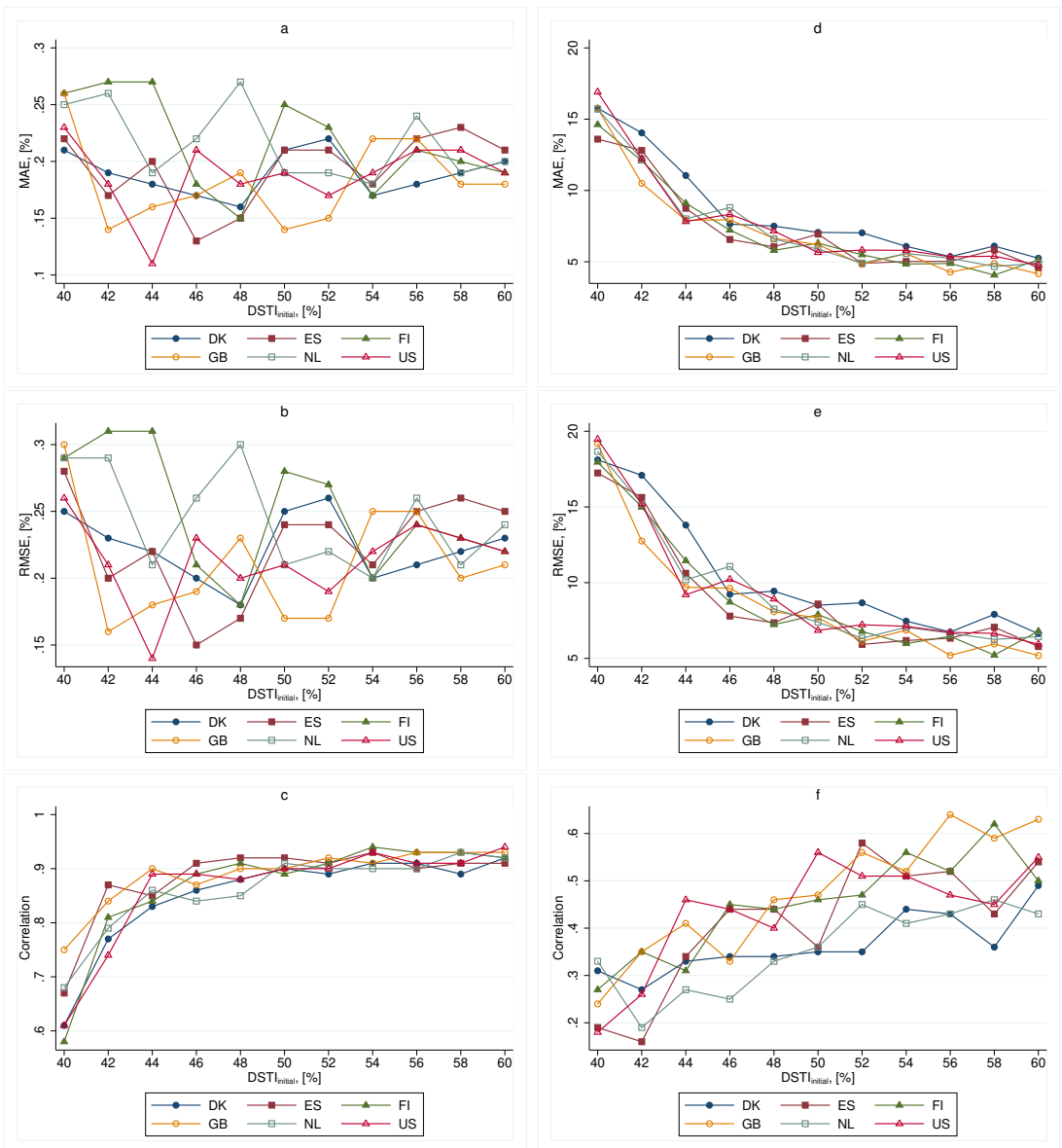

Figure 18: Calibration of initial DSTI and DSTI growth rate path for UK. Panels (a) to (c) correspond to the distance between simulated and historical consumer credit series in rescaled levels and (d) to (f) to annual growth rates.

Finally, results for the UK indicate that indeed the country-specific DSTI path from the BIS database provides the best fit, followed closely by the ES and US scenarios with which it shares a quite similar pattern (see Figure 3 ). Since the direction of improvement is the same for both rescaled and growth rate series, the selected value for initial DSTI's level is set to $56 \%$.

\section{B Validation with inadequate approximation of DSTI}

The results presented in section 3.2 demonstrated the ability of the model to reproduce historical series once input data used are a good approximation of 
the realized ones. In this section is examined the model's performance when some of the utilized data diverge from the actual figures. In particular, are presented the cases of EE and LT where the implemented DSTI is not a good approximation of the historical one as discussed in Appendix A.

The initial values of the Estonian and Lithuanian simulation parameters are presented in Table 7 .

Table 7: Initial setup of the simulation for EE and LT.

\begin{tabular}{ccc} 
Description & Country \\
\hline \hline & EE & LT \\
\hline Average income & 282 & 265 \\
Minimum income & 90 & 110 \\
Gini coefficient of income distribution (\%) & 36 & 35.5 \\
Income distribution shape parameter $(\alpha)$ & 1.280 & 0.816 \\
Income distribution scale parameter $(\lambda)$ & 150 & 190 \\
Unemployment rate (\%) & 12.9 & 15.9 \\
Consumer credit interest rate (\%) & 6.738 & 4.948 \\
Overnight deposit interest rate (\%) & 0.699 & 0.368 \\
DSTI (\%) & 50 & 52 \\
\hline
\end{tabular}

A description of the series used and their time periods is provided in Table 8.

Table 8: The range of the variables used in EE and LT historical scenarios.

\begin{tabular}{ccc} 
Variable & EE & LT \\
\hline \hline Wages \& salaries & $2000 \mathrm{q} 1-2018 \mathrm{q} 1$ & $2000 \mathrm{q} 1-2018 \mathrm{q} 1$ \\
Unemployment rate & $2000 \mathrm{~m} 1-2018 \mathrm{~m} 3$ & $2000 \mathrm{~m} 1-2018 \mathrm{~m} 3$ \\
Consumer credit interest rate & $2005 \mathrm{~m} 1-2018 \mathrm{~m} 3$ & $2005 \mathrm{~m} 3-2018 \mathrm{~m} 3$ \\
Overnight deposit interest rate & $2003 \mathrm{~m} 3-2018 \mathrm{~m} 3$ & $2005 \mathrm{~m} 3-2018 \mathrm{~m} 3$ \\
DSTI path & DK & DK \\
\hline
\end{tabular}




\section{B.1 Validation with the Estonian scenario}

The results for the EE-specific scenario are plotted in Figure 19. The first row presents the results for consumption and the second those for consumer credit. Column-wise, the first column shows the results in levels (rescaled by their sample means), while the last one in annual growth rates.
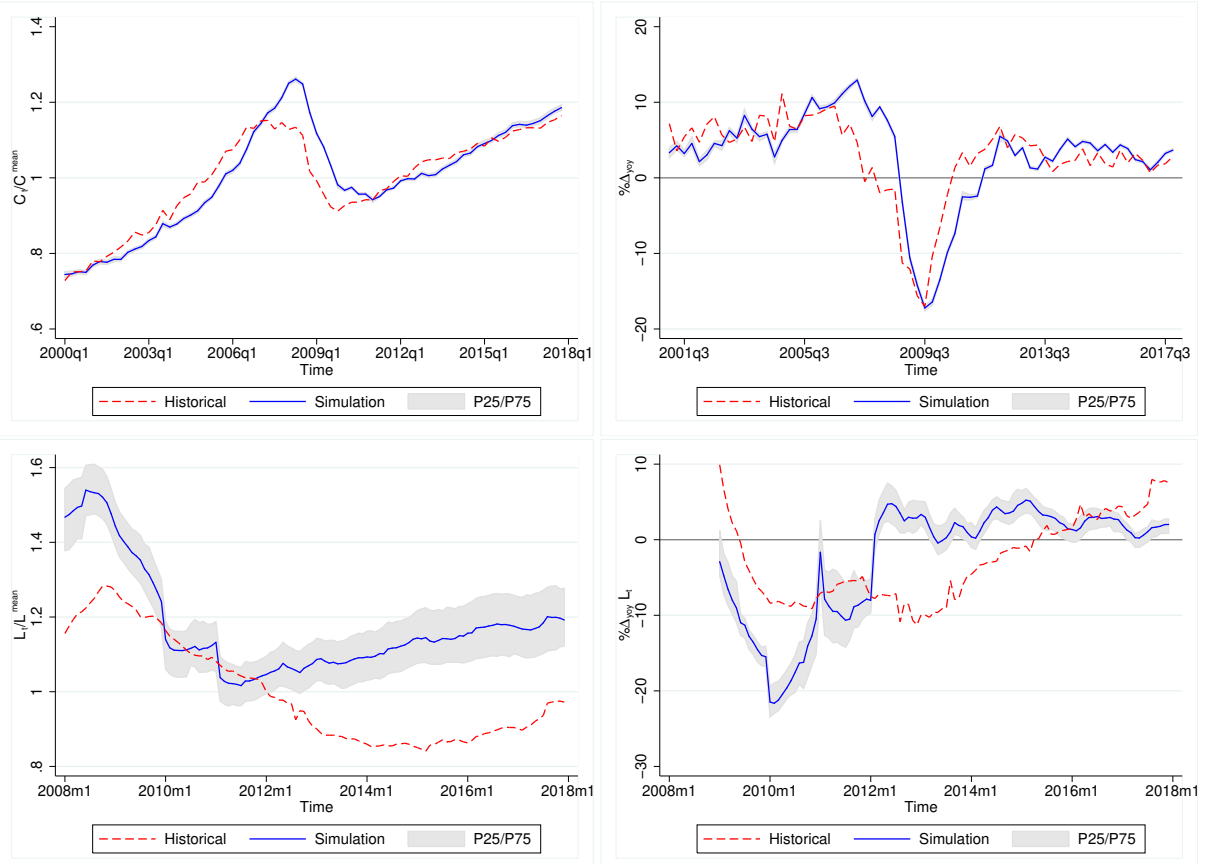

Figure 19: Baseline simulation results for the EE-specific scenario.

As one can see in Figure 19, the simulated series for consumption are in very good agreement with the historical ones both in levels, and in growth rates. On the contrary, results for consumer credit are not as satisfactory. In Table 9 are reported three quantitative measures of the distance between the artificial and actual observations. 
Table 9: Distance and similarity measures between simulated and historical data for EE.

\begin{tabular}{ccccc} 
Variable & Transformation & MAE & RMSE & Correlation \\
\hline \hline \multirow{3}{*}{ Consumption } & $y_{t} / y^{\text {mean }}$ & 0.037 & 0.052 & 0.932 \\
& $\% \Delta_{\text {yoy }}$ & 3.012 & 4.101 & 0.767 \\
\multirow{2}{*}{ Credit } & $y_{t} / y^{\text {mean }}$ & 0.182 & 0.208 & 0.684 \\
& $\% \Delta_{\text {yoy }}$ & 6.233 & 7.418 & 0.389 \\
\hline
\end{tabular}

The quantitative measures in Table 9 corroborate the findings in Figure 19. They reveal a distance of approximately $3 \%$ to $4 \%$ on average and high correlation (above $75 \%$ in growth rates and above $90 \%$ in levels) between the actual and artificial series of consumption. For the case of credit though, results are less encouraging with higher error measures but also substantially lower correlation.

\section{B.2 Validation with the Lithuanian scenario}

The results for the Lithuanian scenario are more promising and are presented in Figure 20. 

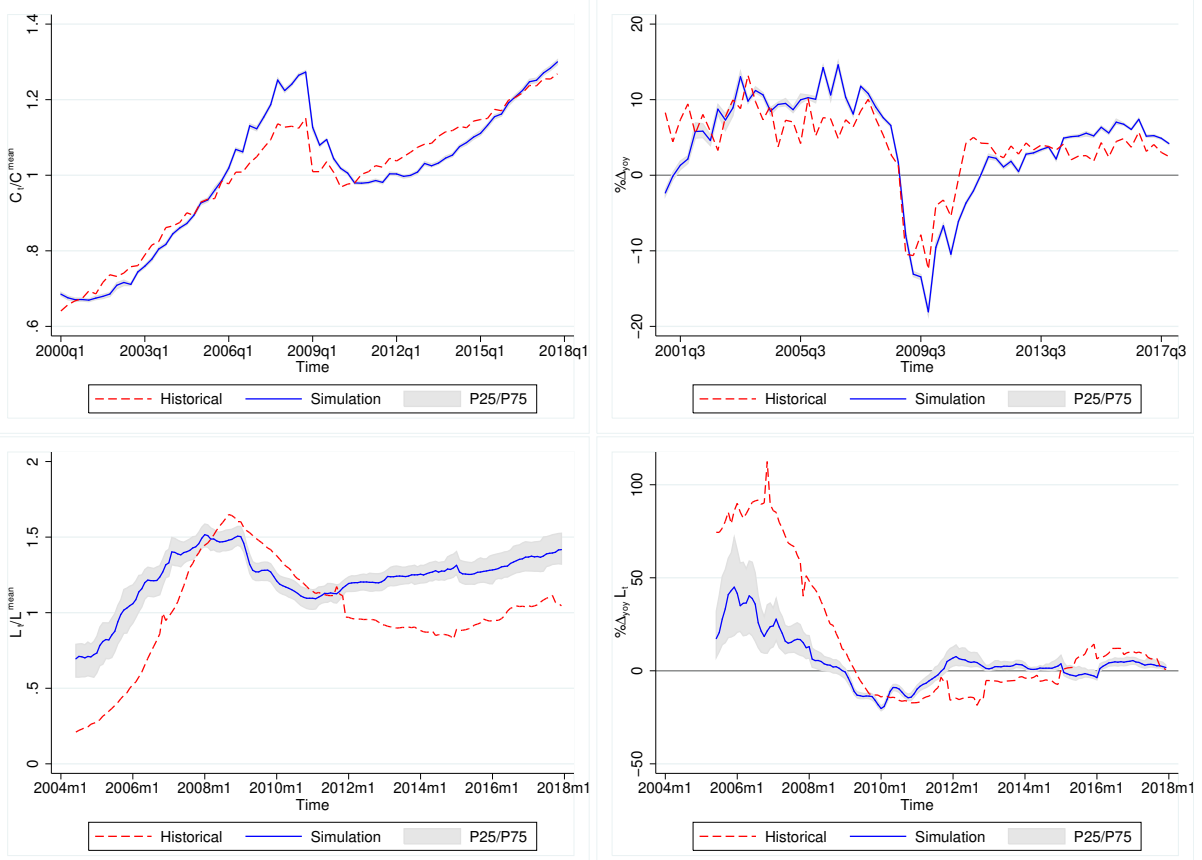

Figure 20: Baseline simulation results for the LT-specific scenario.

As in the case of EE, simulated data for consumption (first row of Figure 20) are almost indiscernible from the observed ones. Credit related series in the second row of Figure 20 show that there is some degree of similarity in distance and synchronicity between artificial and historical data. The patterns both in levels and growth rates are comparable while in the latter even magnitudes are close after 2010. In Table 10 are reported the quantitative measures of distance and similarity between the two series.

Table 10: Distance and similarity measures between simulated and historical data for LT.

\begin{tabular}{ccccc} 
Variable & Transformation & MAE & RMSE & Correlation \\
\hline \hline \multirow{3}{*}{ Consumption } & $y_{t} / y^{\text {mean }}$ & 0.042 & 0.053 & 0.960 \\
& $\% \Delta_{\text {yoy }}$ & 3.066 & 3.830 & 0.829 \\
\multirow{3}{*}{ Credit } & $y_{t} / y^{\text {mean }}$ & 0.285 & 0.322 & 0.784 \\
& $\% \Delta_{\text {yoy }}$ & 18.645 & 27.015 & 0.862 \\
\hline
\end{tabular}

Regarding consumption, the figures in Table 10 demonstrate that indeed 
there is a very good agreement between the two series both in magnitude (their average distance is around $4 \%$ ) as well as in co-movement (correlation ranges between $80 \%$ and $96 \%$ ). Results for credit series show a mixed picture. On the one hand distance measures (MAE and RMSE) reveal large discrepancies which are mainly driven by the period up to 2010. On the other hand, high correlation indicates that the two series move in a strongly synchronized manner. 